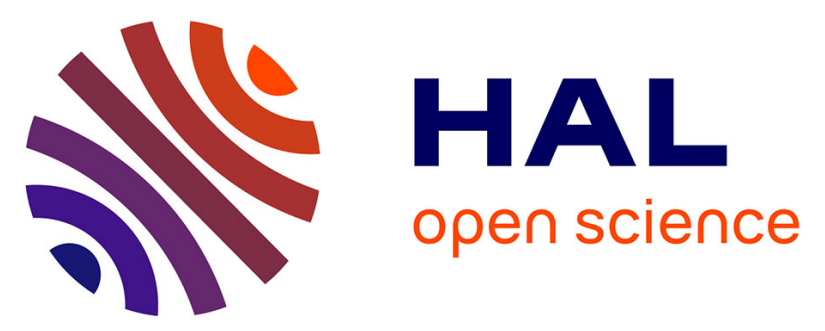

\title{
Al-alkenyl-induced formation of long-chain branched polyethylene via coordinative tandem insertion and chain-transfer polymerization using (nBuCp)2ZrCl2/MAO systems: An experimental and theoretical study
}

\author{
O. Santoro, L. Piola, K. Mc Cabe, O. Lhost, K. den Dauw, A. Vantomme, A. \\ Welle, Laurent Maron, J.-F. Carpentier, E. Kirillov
}

\section{- To cite this version:}

O. Santoro, L. Piola, K. Mc Cabe, O. Lhost, K. den Dauw, et al.. Al-alkenyl-induced formation of long-chain branched polyethylene via coordinative tandem insertion and chain-transfer polymerization using $(\mathrm{nBuCp}) 2 \mathrm{ZrCl} 2 / \mathrm{MAO}$ systems: An experimental and theoretical study. European Polymer Journal, 2021, 154, pp.110567. 10.1016/j.eurpolymj.2021.110567 . hal-03284278

\section{HAL Id: hal-03284278 \\ https://hal.science/hal-03284278}

Submitted on 16 Jul 2021

HAL is a multi-disciplinary open access archive for the deposit and dissemination of scientific research documents, whether they are published or not. The documents may come from teaching and research institutions in France or abroad, or from public or private research centers.
L'archive ouverte pluridisciplinaire HAL, est destinée au dépôt et à la diffusion de documents scientifiques de niveau recherche, publiés ou non, émanant des établissements d'enseignement et de recherche français ou étrangers, des laboratoires publics ou privés. 


\section{Al-Alkenyl-Induced Formation of Long-Chain Branched Polyethylene via Coordinative \\ Tandem Insertion and Chain-Transfer Polymerization Using $(n \mathrm{BuCp})_{2} \mathrm{ZrCl}_{2} / \mathrm{MAO}$ Systems: An Experimental and Theoretical Study}

Orlando Santoro, ${ }^{\mathrm{a}, \uparrow}$ Lorenzo Piola,${ }^{\mathrm{a}, \dagger}$ Karl Mc Cabe,${ }^{\mathrm{c}}$ Olivier Lhost, ${ }^{\mathrm{b}}$ Katty Den Dauw, ${ }^{\mathrm{b}}$ Aurélien Vantomme, ${ }^{\mathrm{b}}$ Alexandre Welle, ${ }^{\mathrm{b}}$ Laurent Maron, ${ }^{\mathrm{c},}$, Jean-François Carpentier, ${ }^{\mathrm{a}, *}$ and Evgueni Kirillov, ${ }^{\mathrm{a},}$

a Univ Rennes, CNRS, Institut des Sciences Chimiques de Rennes (ISCR), UMR 6226, F35042 Rennes, France

b Total Research \& Technology Feluy, Zone Industrielle Feluy C, B-7181 Seneffe, Belgium

c Université de Toulouse, CNRS, INSA, UPS, LPCNO, UMR 5215, 135 avenue de Rangueil, F-31077 Toulouse Cedex 4, France

$\dagger$ Those two authors equally contributed to this work.

* Correspondence to Laurent Maron (laurent.maron@,irsamc.ups-tlse.fr), Jean-François Carpentier (jean-francois.carpentier@univ-rennes1.fr) and Evgueni Kirillov (evgueni.kirillov@univ-rennes1.fr). 


\section{Abstract}

Recently, we have identified the Al-alkenyl species $i \mathrm{BuAl}(\text { oct-7-en-1-yl) })_{2}$ (Al-1) as a promising long-chain branching (LCB) promoter in the ethylene polymerization catalyzed by rac- $\{\mathrm{EBTHI}\} \mathrm{ZrCl}_{2}$-based systems, proposing the incorporation of its alkenyl moiety into the growing polyethylene (PE) chain as a crucial step for LCB formation. The success of the process was attributed to the high copolymerization ability of the selected catalyst. In the present contribution, we aimed at probing the efficiency of Al-1 in combination with catalyst systems based on the unbridged metallocene $\left(n \mathrm{BuCp}_{2} \mathrm{ZrCl}_{2}(\mathbf{Z r}-\mathbf{1})\right.$, namely homogeneous $\mathbf{Z r}$ 1/MAO or heterogeneous MAO on silica-supported-Zr-1/TIBAL (supp-Zr-1/TIBAL); in the literature, such systems are claimed to be less efficient copolymerization catalysts compared to bridged systems (i.e. $r a c-\{\mathrm{EBTHI}\} \mathrm{ZrCl}_{2}$ ). In fact, while the supported catalyst produces only purely linear PEs, branched structures were obtained in the presence of the congener homogenous system. Remarkably, the qualitative rheological data suggest that the extent of LCB formation in such samples is comparable to that of the PEs synthesized under similar reaction conditions with the EBTHI/MAO/Al-1 system. This testifies that the Al-alkenyl species is a suitable LCB promoter, even with metallocenes having quite different copolymerization ability (at least in that series). This was rationalized considering the formation of a $\mathrm{Zr} / \mathrm{Al}$ heterobimetallic species facilitating the $\mathbf{A l - 1}$ incorporation via the coordinative tandem insertion and chain-transfer polymerization mechanism, identified in the previous study, and supported by new DFT computations.

Keywords: Ethylene Polymerization, Al-alkenyl, Long-Chain Branching, Metallocene, Rheology, DFT Calculations 


\section{Introduction}

Metallocene catalysts for olefin polymerization have enabled the production of polyethylene (PE) with high molecular weight and narrow polydispersity [1]. In spite of their improved mechanical properties, such materials generally suffer from poor processability due of their low elasticity and melt viscosity. Nevertheless, it has been shown that these properties can be improved by introducing long-chain branching (LCB) to linear polyolefins [2-4]. Different methodologies have been developed, such as the ethylene copolymerization with vinylterminated polyolefins (macromonomers) [5,6], copolymerization with a non-conjugated $\alpha, \omega$ diene [7-11], as well as processes involving radical mechanisms [12-18]. Nevertheless, the materials produced with these methodologies generally exhibit complex molecular structures and/or uneven branch distribution. Better control over long-chain branching formation can be achieved by using metal-alkenyl compounds serving as both co-catalysts and LCB-promoters $[19,20]$. In this scenario, we have identified, in a previous recent study, the crucial role of the Al-alkenyl compound $i \mathrm{BuAl}(\text { oct-7-en-1-yl })_{2}(\mathrm{Al}-1)$ as an LCB-promoter in the polymerization of ethylene catalyzed by homogeneous $\mathrm{rac}-\{\mathrm{EBTHI}\} \mathrm{ZrCl}_{2} / \mathrm{MAO}$ or heterogeneous MAO on silica-supported-rac-\{EBTHI $\} \mathrm{ZrCl}_{2} / \mathrm{TIBAL}$ systems

(EBTHI ethylenebis(tetrahydroindenyl)) [21]. In these systems, LCB was thought to originate from the (1,2-) insertion of a pending oct-7-enyl moiety into the $\mathrm{Zr}-\mathrm{C}_{\text {Polymeryl }}$ bond, followed by $\mathrm{Al} \rightarrow \mathrm{Zr}$ transmetallation, eventually generating a growing side-chain (Scheme 1). On the contrary, protonolysis of the intermediate species would lead to the formation of $n$-hexyl short-chain branches (SCB). Although the discrimination between LCB and SCB in the final polymer could not be performed by means of ${ }^{13} \mathrm{C}$ NMR spectroscopy [21], the use of this Al-vinyl transfer agent (AVTA) resulted in a marked change in the rheological behavior of the PEs, unambiguously consistent with LCB generation. 


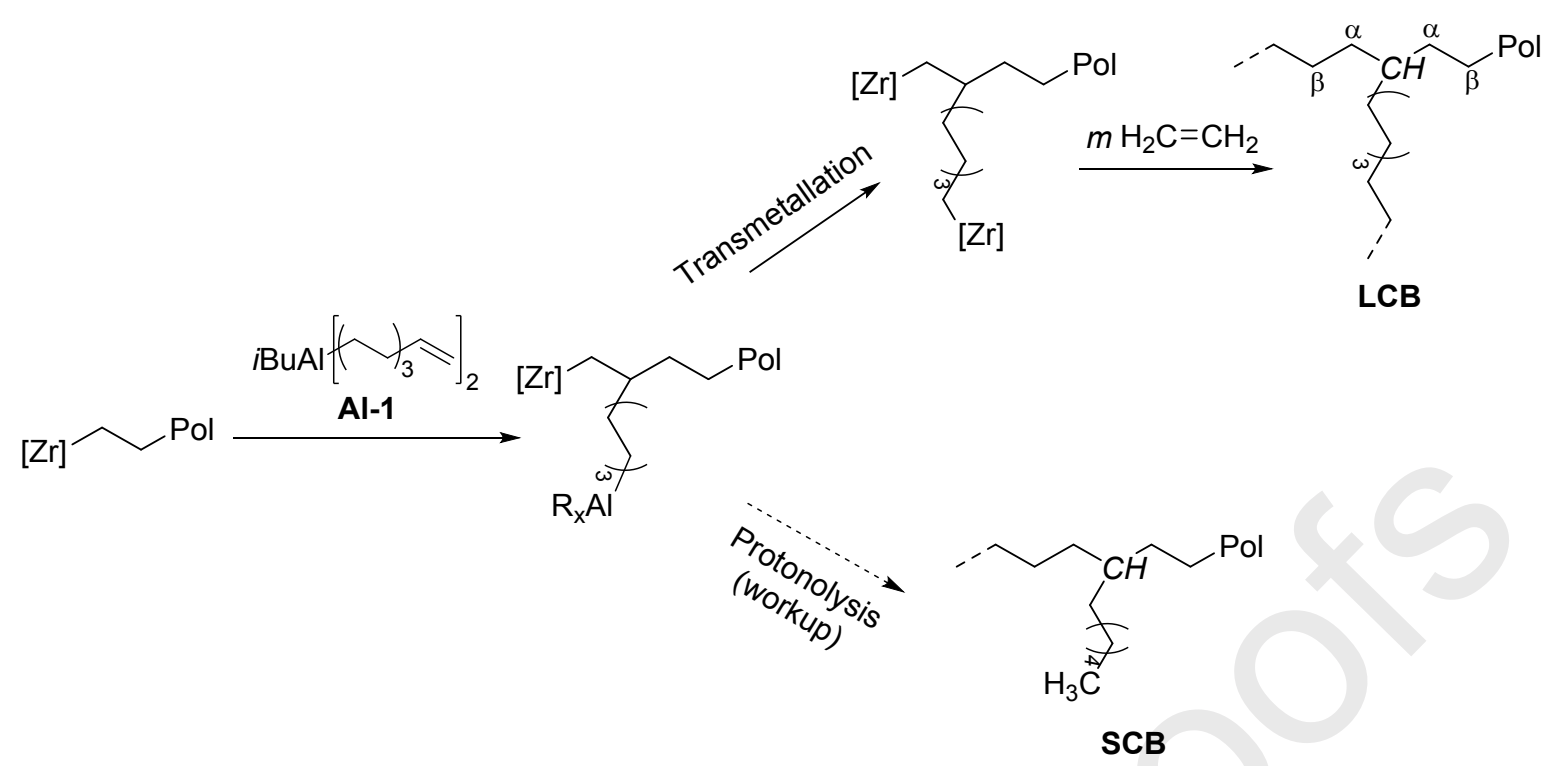

Scheme 1. Possible generation pathway of short- (SCB) and long-chain branching (LCB) obtained in the presence of Al-vinyl transfer agent (AVTA) Al-1 (Pol= polymeryl chain) [21].

Herein, we report on the extension of the same protocol employing Al-1 in combination with catalytic systems based on the unbridged metallocene $(n \mathrm{BuCp})_{2} \mathrm{ZrCl}_{2}(\mathbf{Z r}-\mathbf{1}$, Chart 1), namely homogeneous $\mathbf{Z r - 1 / M A O}$ or heterogeneous MAO on silica-supported-Zr-1/TIBAL (supp-Zr-1/TIBAL). Such catalysts were selected to probe the efficiency of Al-1 as LCBpromoter based on two main factors:

1) The combination $\mathbf{Z r - 1 / M A O}$ has been reported to hardly incorporate macromonomers, eventually affording linear PEs essentially void of any LCB [22-27];

2) It has been demonstrated that with $\mathbf{Z r - 1}$ the incorporation of such comonomers as 1hexene occurs to a much lower extent (ca. a half) as compared with bridged metallocene systems $[22,23,24,28]$. Thus, the insertion of the pending vinyl moiety of Al-1 reagent during the polymerization with $\mathbf{Z r} \mathbf{- 1}$ could be more challenging than in the case of the previously investigated rac-\{EBTHI $\} \mathrm{ZrCl}_{2}$-based systems [21]. 


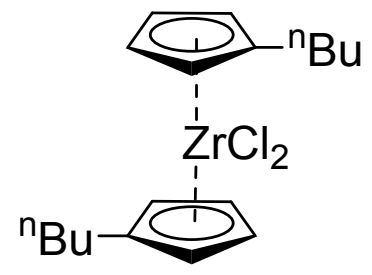

Chart 1. Structure of $(n \mathrm{BuCp})_{2} \mathrm{ZrCl}_{2}(\mathbf{Z r}-\mathbf{1})$.

\section{Experimental section}

\subsection{Materials}

All manipulations were performed under purified argon atmosphere using standard Schlenk or glovebox techniques. Dry toluene was obtained from a MB-SPS-800 solvent purification system and stored over molecular sieves $3 \AA$. Deuterated benzene was dried over calcium hydride and distilled under reduced pressure prior to use. Precatalysts $(n \mathrm{BuCp})_{2} \mathrm{ZrCl}_{2}$, $(n \mathrm{BuCp})_{2} \mathrm{ZrCl}_{2}$-supported onto silica (from PQ, D50: $\left.40 \mu\right)(0.4 \mathrm{wt} \% \mathrm{Zr})$ and MAO $(30 \mathrm{wt} \%$ solution in toluene; contains ca. $10 \mathrm{wt} \%$ of free $\mathrm{AlMe}_{3}$ ) were provided by Total Petrochemicals. Al-1 was synthesized as reported previously [21]. Other starting materials were purchased from Fluorochem and Acros and used as received.

\subsection{Methods}

NMR spectra of M-alkenyl species were recorded on Bruker AC-400 spectrometer in Teflonvalve NMR tubes at $25{ }^{\circ} \mathrm{C} .{ }^{1} \mathrm{H}$ and ${ }^{13} \mathrm{C}$ NMR chemical shifts are reported in ppm vs. $\mathrm{SiMe}_{4}$ (0.00) as determined by reference to the residual solvent peak. ${ }^{13} \mathrm{C}\left\{{ }^{1} \mathrm{H}\right\}$ NMR analyses of PE samples were performed at the TOTAL Research and Technology Feluy (TRTF) research center in Feluy (Belgium) on a AM-500 Bruker spectrometer equipped with a cryoprobe using the following conditions: solutions of ca. $200 \mathrm{mg}$ of polymer in a mixture 5:1 of 1,2,4trichlorobenzene/ $\mathrm{C}_{6} \mathrm{D}_{6}$ mixture at $135^{\circ} \mathrm{C}$ in $10 \mathrm{~mm}$ tubes, inverse-gated experiment, pulse angle $=90^{\circ}$, delay $=11 \mathrm{~s}$, acquisition time $=1.25 \mathrm{~s}$, number of scans $=6,000$. 
DSC measurements were performed on a SETARAM Instrumentation DSC 131 differential scan calorimeter at a heating rate of $10{ }^{\circ} \mathrm{C} \cdot \mathrm{min}^{-1}$, first and second runs were recorded after cooling to $30{ }^{\circ} \mathrm{C}$; the melting and crystallization temperatures reported in tables were determined on the second run.

GPC analyses of PE samples were carried out in 1,2,4-trichlorobenzene at $135^{\circ} \mathrm{C}$ at the TRTF research center in Feluy (Belgium), using polystyrene standards for universal calibration.

\subsection{Rheological measurements.}

Samples for rheological measurements were prepared as follows: ca. $900 \mathrm{mg}$ of polymer were stabilized with $1 \mathrm{wt} \%$ of BHT or IRGANOX 1010 and press-molded into circular disks (2 mm thick and $20 \mathrm{~mm}$ diameter) at 190 C. Oscillatory experiments were carried out on an ARES G2 equipment (TA Instruments) in parallel plate configuration under the following conditions: shear strain $(\gamma) 10 \%$, angular frequencies $(\omega)$ from 0.1 to $250 \mathrm{rad} \cdot \mathrm{s}^{-1}, \mathrm{~T}=190{ }^{\circ} \mathrm{C}, \mathrm{N}_{2}$ atmosphere.

\subsection{Polymerization procedures}

\subsubsection{Homogeneous conditions}

Experiments at $\mathrm{P}_{\text {(ethylene) }}=4$ barg. Polymerization were performed in a $300 \mathrm{~mL}$-high-pressure glass reactor equipped with a mechanical stirred (Pelton turbine) and externally heated with a double mantle with thermostated circulating water bath. The reactor was purged three times (vacuum-argon cycles) and charged subsequently with toluene $(150 \mathrm{~mL}), \mathrm{MAO}(1.5 \mathrm{~mL}$ of a $30 \mathrm{wt} \%$ solution in toluene) and ethylene. The system was thermally equilibrated at the desired temperature for $30 \mathrm{~min}$. The ethylene pressure was decreased to 1 bar and a mixture of catalyst precursor and co-reactant in toluene (ca. $2 \mathrm{~mL}$ ) was added by syringe. The ethylene pressure 
was increased to 4 barg (kept constant by means of a back regulator) and the reaction mixture was stirred for the desired time. The temperature inside the reactor was monitored using a thermocouple. The polymerization was stopped by venting the reactor and quenching with a $10 \mathrm{wt} \%$ solution of aqueous $\mathrm{HCl}$ in methanol (ca. $3 \mathrm{~mL}$ ). The polymer was precipitated from methanol $(200 \mathrm{~mL})$ and $35 \mathrm{wt} \%$ aqueous $\mathrm{HCl}(2 \mathrm{~mL})$ was added to dissolve possible catalyst residues. The polymer was collected by filtration, washed with methanol $(200 \mathrm{~mL})$ and dried under reduced pressure at $65^{\circ} \mathrm{C}$ overnight.

Experiments at $\mathrm{P}_{(\text {ethylene) }}=9$ barg. Polymerizations were performed in triplicates in a 24-slot high-throughput screening reactor in $50 \mathrm{~mL}$-glass vials. Under nitrogen atmosphere, each vial was equipped with a magnetic stirrer and loaded with heptane $(25 \mathrm{~mL})$, a toluene solution of the activated catalyst $\left(50 \mu \mathrm{L}, \mathrm{Al}_{\mathrm{MAO}} / \mathbf{Z r}-\mathbf{1} 4,500\right)$ and the required amount of $\mathbf{A l - 1}(0,50,125$ or $225 \mu \mathrm{L}$ of a $10 \%$ solution in hexanes). The vials were sealed with a Crimp Cap and introduced in the corresponding slots of the reactor thermostated at $60{ }^{\circ} \mathrm{C}$. The reactor was closed and pressurized with ethylene at 10 bar (the gas is introduced in the vials through a needle piercing the septum of the crimp caps). The reaction was stopped after 15 minutes by venting the reactor. The polymer samples were collected and dried in air at room temperature for 16 hours and under reduced pressure at $50{ }^{\circ} \mathrm{C}$ for 3 hours.

\subsubsection{Heterogeneous conditions}

The tests were performed in a parallel reactor system integrating six $130 \mathrm{~mL}$-stainless steel reactors equipped with a thermocouple, a pressure transducer and constant pressure regulator. Each reactor features an antechamber. Each vessel was loaded with iso-butane (75 mL), 1hexene (2.44 wt\%), $\mathrm{H}_{2}(800 \mathrm{ppm})$ and ethylene (23.8 bar) and the temperature was equilibrated at $85^{\circ} \mathrm{C}$ for $30 \mathrm{~min}$. Each antechamber was charged with heptane $(2 \mathrm{~mL})$, the supported catalyst $(2.0 \mathrm{mg})$ and the desired amount of TIBAL or Al-1. The polymerizations were started by pressurizing these mixtures in the reactors and were stopped after 1 hour by venting the 
reactors. The polymer samples were collected and left to dry in air at room temperature overnight.

\section{Results and discussion}

3.1 Polymerization of ethylene catalyzed by $\mathbf{Z r - 1 / M A O / A l - 1 ~ h o m o g e n e o u s ~ s y s t e m s . ~}$

Ethylene polymerization tests were first performed under homogeneous conditions (Table 1). Two benchmark samples, namely PE1 and PE2, were synthesized in the absence of Al-1 and under different reaction conditions (Table 1, entries 1 and 2) [29]. Although the thermal properties of the two materials were found to be in the same range $\left(134\right.$ and $118{ }^{\circ} \mathrm{C}$ for $T_{\mathrm{m}}$ and $T_{\text {cryst }}$, respectively), PE2 exhibited higher molecular weight and broader polydispersity than PE1. Finally, a test was performed in the presence of 500 equiv. of Al-1 under the same reaction conditions employed for PE2 (Table 1, entry 3). The polymer obtained (PE3) showed $M_{\mathrm{w}}$ and PDI comparable to those of PE2, albeit exhibiting sensibly lower $T_{\mathrm{m}}$ and $T_{\text {cryst }}$ values (129.1 and $115.4{ }^{\circ} \mathrm{C}$, respectively). The crystallinity values of PE2 and PE3 were found to be rather similar (41 and 37\%, respectively), albeit significantly lower than that of PE1 (62\%).

Table1. Polymerization of ethylene in the presence of homogeneous catalyst system $\mathbf{Z r}-1 / \mathrm{MAO}(/ \mathbf{A l}-1) .^{\mathrm{a}}$

\begin{tabular}{|c|c|c|c|c|c|c|c|c|c|c|}
\hline Entry & $\begin{array}{l}\text { Sample } \\
\text { ID }\end{array}$ & $\begin{array}{c}\text { MAOO } \\
{[\mathrm{Al}] /[\mathrm{Zr}]}\end{array}$ & $\begin{array}{c}\text { Al-1 } \\
{[\mathrm{Al}] /[\mathrm{Zr}]}\end{array}$ & $\begin{array}{c}T_{\text {pol }} \\
{\left[{ }^{\circ} \mathrm{C}\right]}\end{array}$ & $\begin{array}{l}\text { Productivity } \\
{\left[\mathrm{kg}_{\mathrm{Pol} /} / \mathrm{kg}_{\mathrm{cat}} \times \mathrm{h}\right]}\end{array}$ & $\begin{array}{c}T_{\mathrm{m}}^{\mathrm{b}} \\
{\left[{ }^{\circ} \mathrm{C}\right]}\end{array}$ & $\begin{array}{c}T_{\text {cryst }^{b}}{ } \\
{\left[{ }^{\circ} \mathrm{C}\right]}\end{array}$ & $\begin{array}{c}\boldsymbol{M}_{\mathbf{w}}{ }^{\mathrm{c}} \\
{\left[\times 10^{-3}\right]}\end{array}$ & $M_{\mathrm{w}} / M_{\mathrm{n}}^{\mathrm{c}}$ & $\begin{array}{c}\text { Crystallinity }^{\mathrm{d}} \\
{[\mathrm{wt} . \%]}\end{array}$ \\
\hline $1^{\mathrm{e}}$ & PE1 & 1,000 & 0 & 80 & 42,400 & 134.8 & 118.4 & 65 & 2.6 & 61.7 \\
\hline 2 & PE2 & 5,000 & 0 & 60 & 42,000 & 134.4 & 118.7 & 109 & 3.7 & 41.0 \\
\hline 3 & PE3 & 4,500 & 500 & 60 & 43,200 & 129.1 & 115.4 & 116 & 4.1 & 37.2 \\
\hline
\end{tabular}

${ }^{a}$ Polymerization conditions: $300 \mathrm{~mL}$-high pressure glass reactor; solvent: toluene, $150 \mathrm{~mL}$; $\mathrm{P}($ ethylene $)=4 \mathrm{barg}$; time $=15 \mathrm{~min}$; $[\mathrm{Zr}]_{0}=10 \mu \mathrm{M},\left[\mathrm{Al}_{\mathrm{MAO}}\right] /[\mathrm{Zr}]_{0}=4,500 .{ }^{b}$ Determined by DSC from second run. ${ }^{c}$ Determined by GPC. ${ }^{d}$ Calculated from $\left[\left(\Delta H_{\mathrm{m}} / \Delta H_{\mathrm{m}}^{0}\right) \times 100\right]$, where $\Delta H_{m}$ is the heat of fusion of the sample (in $\mathrm{J} / \mathrm{g}$ ) determined by DSC and $\Delta H^{0}{ }_{m}$ is the theoretical heat of fusion for $100 \%$ crystalline $\mathrm{PE}(293 \mathrm{~J} / \mathrm{g})$. [30] ${ }^{e}[\mathrm{Zr}]=5 \mu \mathrm{M}, \mathrm{t}=10 \mathrm{~min}, \mathrm{P}=2 \mathrm{barg}$.

The structure of PE1-PE3 was investigated by melt rheology (Figure 1). The variation of the modulus of the complex viscosity $\left(\left|\eta^{*}\right|\right)$ as a function of the frequency $(\omega)$ for PE1 displayed low viscosity at low frequency (ca. 1,600 Pas at $0.1 \mathrm{rad} \cdot \mathrm{s}^{-1}$ ) and weak shear thinning, while the Newtonian plateau for PE2 and PE3 was found at higher $\left|\eta^{*}\right|$ values (Figure 1a). This 
is clearly due to the higher $M_{\mathrm{w}}$ value of these two samples compared to that of PE1. On the other hand, the shear-thinning exhibited by PE3 was significantly more pronounced than that of PE2. This indicates a higher, clearly detected by rheology, LCB concentration achieved in the presence of the Al-alkenyl co-reactant.
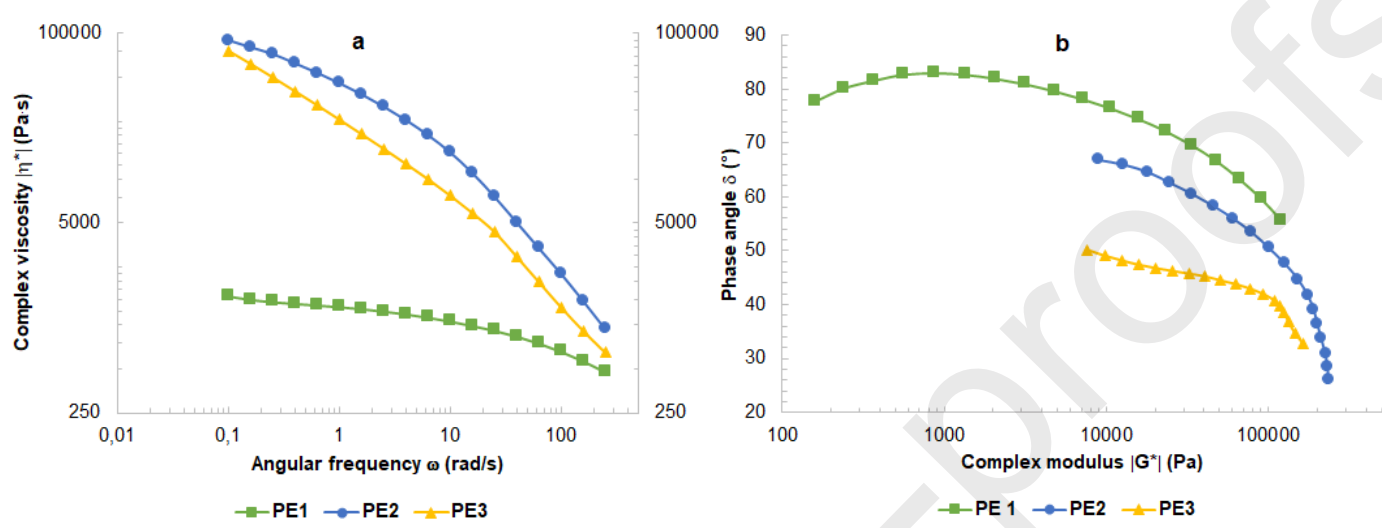

Figure 1. Rheological properties of the PEs obtained with Zr-1/MAO/Al-1 systems: (a) modulus of complex viscosity $\left(\left|\eta^{*}\right|\right)$ vs angular frequency $(\omega)$ plot; (b) vGP plot. Shear strain $(\gamma)$ 10\%, angular frequencies $(\omega)$ from 0.1 to $250 \mathrm{rad} \cdot \mathrm{s}^{-1}$, and $\mathrm{T}=190{ }^{\circ} \mathrm{C}$.

Interestingly, the curves on the van Gurp-Palmen plot (vGP plot) described by PE1PE3 tend to phase angles lower than $90^{\circ}$, that is the value observed for purely linear samples (Figure 1b) [31,32]. Hence, a low LCB content was detected for the samples prepared without Al-1 (vide infra). For PE1, the maximum phase angle $\delta$ achieved is ca. $85^{\circ}$; in addition, the curve presents a decreasing $\delta$ towards the lowest $\left|\mathrm{G}^{*}\right|$ values. We assume to be in proximity of a minimum which could not be observed, possibly because of the limited frequency range investigated $\left(\omega=0.1-250 \mathrm{rad} \cdot \mathrm{s}^{-1}\right)$. Indeed, the presence of a minimum in a vGP plot is indicative of PEs having branched architectures [33-36]. In turn, PE2 exhibited a $\delta$ value at low $\left|\mathrm{G}^{*}\right|$ of ca. $70^{\circ}$. Such further decrease of the phase angle was attributed to the broader polydispersity of the sample compared to that of PE1 $\left(M_{\mathrm{w}} / M_{\mathrm{n}}=3.7 v s 2.6\right.$, respectively) [31]. Eventually, an even lower $\delta$ value (ca. $50^{\circ}$ ) was observed for PE3, the polymer obtained in the reaction performed in the presence of Al-1. Given that the PDI values of this sample (ca. 
4.1) was close to that of PE2, such different rheological response was accounted to a much larger formation of LCB promoted by the Al co-reactant [37]. Notably, the rheological fingerprints of PE3 are comparable to those of the PEs synthesized under similar reaction conditions with the previously reported EBTHI/MAO/Al-1 system (Figure 2) [21]; this suggests that a similar LCB density can be achieved with the Al-alkenyl co-reactant, regardless of the metallocene employed. This is remarkable, considering the very different comonomer incorporation ability of the two catalysts (EBTHI $>>$ Zr-1) [28]. Nevertheless, it has to be noted that the reactivity of Al-1 could significantly differ from that of a conventional comonomer (i.e. 1-hexene). In fact, the insertion of the pending vinyl group of the Al-alkenyl could be facilitated by the formation of an intermediate $\mathrm{Zr} / \mathrm{Al}$ heterobimetallic species (vide infra, Section 3.3 - DFT computations).

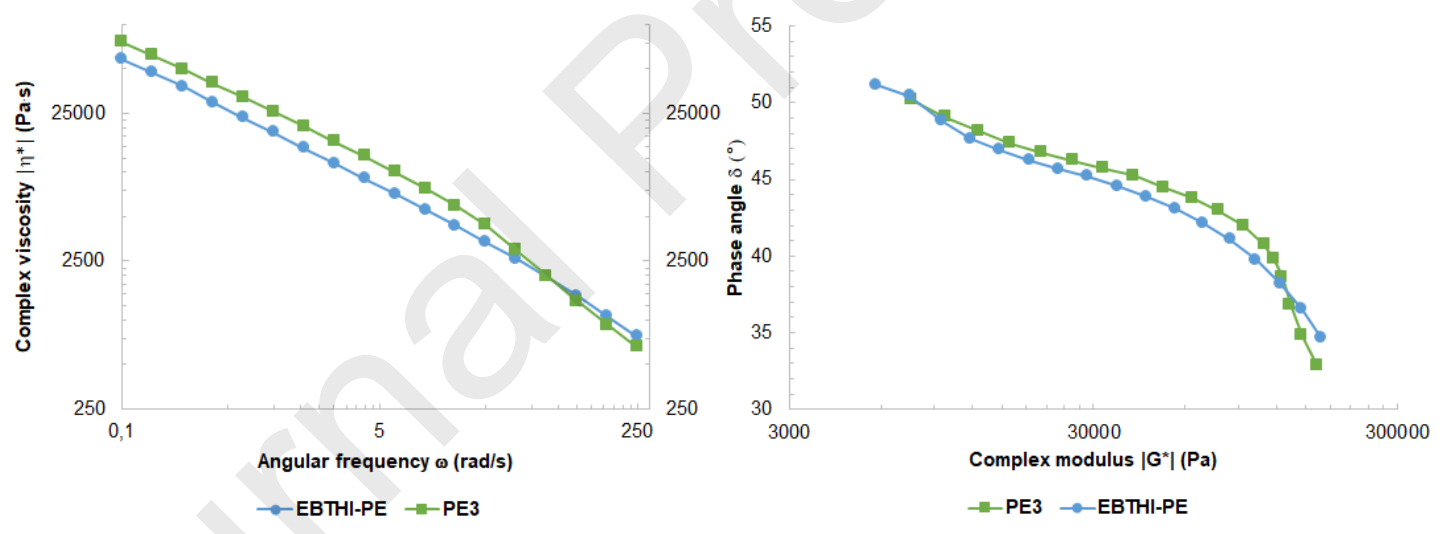

Figure 2. Comparison between the rheological properties of PE3 and that of the PE synthesized under similar conditions with the EBTHI/MAO/Al-1 system (EBTHI-PE) [21]. Left: modulus of complex viscosity $\left(\left|\eta^{*}\right|\right)$ vs angular frequency $(\omega)$ plot; Right: vGP plot. Shear strain $(\gamma) 10 \%$, angular frequencies $(\omega)$ from 0.1 to $250 \mathrm{rad} \cdot \mathrm{s}^{-1}$, and $\mathrm{T}=190^{\circ} \mathrm{C}$. For EBTHI-PE: $M_{\mathrm{w}}=94.0 \mathrm{kDa}$ and $M_{\mathrm{w}} / M_{\mathrm{n}}=3.6$.

The low LCB content of PE1 and PE2 was also confirmed by NMR spectroscopy. In fact, the ${ }^{13} \mathrm{C}\left\{{ }^{1} \mathrm{H}\right\}$ NMR spectra of the two samples show the presence of two resonances, yet of very low intensity but clearly discernible, compatible with the $C$-atoms in $\alpha$ - and $\beta$-positions with respect to the tertiary carbon at the branching point of the LCB $\left(\delta_{\mathrm{C}} 34.62\right.$ and $27.36 \mathrm{ppm}$, 
respectively; see the Supporting Information, Figures S3 and S4 for PE1 and PE2, respectively) [38]. In turn, the ${ }^{13} \mathrm{C}\left\{{ }^{1} \mathrm{H}\right\}$ NMR spectrum of PE3 indicated a higher content of methine- and methyl groups (38 and 14 ppm, respectively) compared to the other two samples (see the Supporting Information, Figure S5), proving that Al-1 was incorporated into the growing polymer chain. Nevertheless, the LCB quantification by ${ }^{13} \mathrm{C}$ NMR spectroscopy for this sample could not be achieved due to the limitations of the technique. In fact, the clear discrimination between LCB and hexyl- fragments (that would originate by the insertion of Al1 followed by hydrolysis; see Scheme 1) cannot be achieved by means of this analytical tool $[21,39]$.

The unexpected presence of a small amount of LCB in PE1 and PE2 is likely the result of minimal incorporation of the concomitantly formed vinyl group-terminated macromonomers, even though such event is much less favourable with $\mathbf{Z r - 1}$ than for silylbis(indenyl) (SBI) or ethylenebis(indenyl) (EBI) catalyst systems [23]. This could be due to a poor reactor control, causing mass-transfer problems [22]. The formation of the polymer allegedly caused an uneven ethylene distribution, hence a local decrease of monomer concentration around the active metal centers. In this scenario, the insertion of in situ-formed macromonomers, eventually leading to LCB polymers, would be favored. In fact, the formation of branching by the $\mathbf{Z r - 1 / M A O}$ system cannot be excluded when sufficiently low ethylene pressures (i.e. 0.5 bar) are employed [22]. In order to corroborate this assumption, a second set of polymerizations was performed at higher ethylene pressure (9 barg, Table 2). Upon increasing the amount of Al-1, the improvement of the productivity and the drop of $T_{\mathrm{m}}$ and polymer crystallinity were observed. It has to be noted that PE6 and PE7, prepared in the presence of Al-1/Zr-1 of 500 and 1000, respectively, exhibited the same thermal features (Table 2, entries 3 and 4). This suggested that amounts of co-reactant above 500 equiv. exert no significant effect on the nature of the final products. 
Table 2. Polymerization of ethylene in the presence of homogeneous catalyst system $\mathbf{Z r}-\mathbf{1} / \mathrm{MAO}(/ \mathbf{A l}-\mathbf{1})$ at high monomer pressure. ${ }^{\mathrm{a}}$

\begin{tabular}{cccccccccc}
\hline Entry & $\begin{array}{c}\text { Sample } \\
\text { ID }\end{array}$ & $\left.\begin{array}{c}\text { MAO } \\
{[\mathrm{Al}] /[\mathrm{Zr}]}\end{array}\right] \begin{array}{c}\mathbf{A l}-1 \\
{[\mathrm{Al}] /[\mathrm{Zr}]}\end{array}$ & $\begin{array}{c}\boldsymbol{T}_{\text {pol }} \\
{\left[{ }^{\circ} \mathrm{C}\right]}\end{array}$ & $\begin{array}{c}\text { Productivity } \\
{\left[\mathrm{kg}_{\mathrm{Pol}} / \mathrm{kg}_{\mathrm{cat}} \times \mathrm{h}\right]}\end{array}$ & $\begin{array}{c}\boldsymbol{T}_{\mathbf{m}}{ }^{\mathrm{b}} \\
{\left[{ }^{\circ} \mathrm{C}\right]}\end{array}$ & $\begin{array}{c}\boldsymbol{M}_{\mathbf{w}}{ }^{\mathrm{c}} \\
{\left[\times 10^{-3}\right]}\end{array}$ & $\boldsymbol{M}_{\mathbf{w}} / \boldsymbol{M}_{\mathbf{n}}{ }^{\mathrm{c}}$ & $\begin{array}{c}\text { Crystallinity }^{\mathrm{d}} \\
{[\mathrm{wt} . \%]}\end{array}$ \\
\hline 1 & PE4 & & 0 & & 38,400 & 131.9 & & & 53.9 \\
2 & PE5 & 4,500 & 100 & \multirow{2}{*}{60} & 37,600 & 132.6 & & Insoluble Samples & 52.8 \\
3 & PE6 & & 500 & & 46,400 & 130.2 & & 45.0 \\
4 & PE7 & & 1000 & & 42,400 & 130.0 & & & 48.9 \\
\hline
\end{tabular}

${ }^{\text {a }}$ Polymerization conditions: $50 \mathrm{~mL}$ glass reactor; solvent: heptane, $25 \mathrm{~mL} ; \mathrm{P}_{(\text {ethylene) }}=9$ barg; time $=15 \mathrm{~min} ;[\mathrm{Zr}]_{0}=$ $2.5 \mu$ M. ${ }^{b}$ Determined by DSC from second run. ${ }^{\mathrm{c}}$ Determined by GPC. ${ }^{\mathrm{d}}$ Calculated from $\left[\left(\Delta H_{\mathrm{m}} / \Delta H^{0} \mathrm{~m}\right) \times 100\right]$, where $\Delta H_{\mathrm{m}}$ is the heat of fusion of the sample (in $\mathrm{J} / \mathrm{g}$ ) determined by DSC and $\Delta H^{0}{ }_{\mathrm{m}}$ is the theoretical heat of fusion for $100 \%$ crystalline PE (293 J/g). [30].

The samples could not be analyzed by GPC due to their insolubility in 1,2,4-trichlorobenzene at $135{ }^{\circ} \mathrm{C}$, indicating the formation of high molecular weight/crosslinked species. The rheological fingerprints of these PEs (Figure 3) were consistent with these observations. In fact, all samples displayed high viscosities at low frequencies (>700 MPas) with strong shear thinning (Figure 3a). Interestingly, the vGP curves of these materials tend to phase angles spanning from 40 and $50^{\circ} \mathrm{C}$ (Figure 3b), indicative of LCB-PEs. While for PE5-PE7 this can be accounted to the use of Al-1, the formation of branches in PE4 could, once again, only be attributed to the formation/insertion of macromonomers.
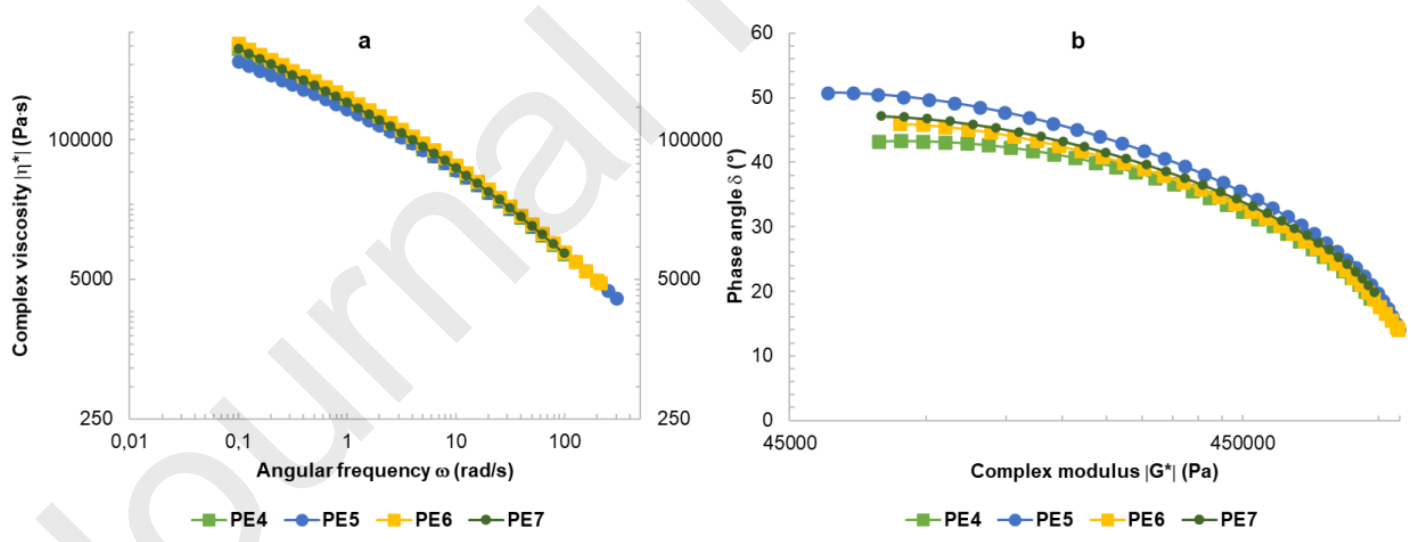

Figure 3. Rheological properties of the PEs obtained with $\mathbf{Z r - 1 / M A O / A l - 1 ~ s y s t e m s ~ a t ~ h i g h e r ~ e t h y l e n e ~ p r e s s u r e ~}$ (PE4-PE7). (a) modulus of complex viscosity $\left(\left|\eta^{*}\right|\right)$ vs angular frequency $(\omega)$ plot; (b) vGP plot. Shear strain $(\gamma)$ $10 \%$, angular frequencies $(\omega)$ from 0.1 to $250 \mathrm{rad} \cdot \mathrm{s}^{-1}$, and $\mathrm{T}=190{ }^{\circ} \mathrm{C}$.

3.2 Polymerization of ethylene catalyzed by supp-Zr-1/TIBAL/Al-1 heterogeneous systems. 
Since in an industrial set-up the synthesis of polymers is typically carried out under heterogeneous conditions, the effect of Al-1 was investigated also in combination with the MAO-on-silica supported version of the catalyst (supp-Zr-1). The tests were performed with a parallel reactor system in the presence of 1-hexene as comonomer (2.44 wt\%) [40] under 25 barg of ethylene. As highlighted in Table 3, no effect of the co-catalyst on the molecular- and thermal features of the PEs was observed. In fact, $M_{\mathrm{w}}$, polydispersity and crystallinity as well as the melt flow index (MI2) [41] and the $T_{\mathrm{m}}$ of the samples remained unaltered, regardless of the amount of Al-1 employed. A drop of productivity was observed for amounts of Al-1 higher than $200 \mathrm{ppm}$ (Table 3, entries 4-6). By performing the reaction in the absence of 1-hexene (entries 7 and 8), an expected decrease of activity, along with the broadening of $M_{\mathrm{w}} / M_{\mathrm{n}}$, were detected. Due to the absence of SCB, both the $T_{\mathrm{m}}$ and the crystallinity of PE14 and PE15 were also significantly higher than those of PE8-PE13 $\left(132{ }^{\circ} \mathrm{C}\right.$ vs $122{ }^{\circ} \mathrm{C}$ and $70 \%$ vs $53 \%$, respectively).

Table3. Polymerization of ethylene in the presence of supp-Zr-1 /TIBAL/Al-1. ${ }^{a}$

\begin{tabular}{|c|c|c|c|c|c|c|c|c|}
\hline Entry & $\begin{array}{c}\text { Co-catalyst } \\
{[\mathrm{ppm}]}\end{array}$ & $\begin{array}{c}\text { Sample } \\
\text { ID }\end{array}$ & $\begin{array}{c}\text { Productivity } \\
{\left[\mathrm{kg}_{\mathrm{Pol}} / \mathrm{kg}_{\mathrm{cat}} \times \mathrm{h}\right]}\end{array}$ & $\begin{array}{c}\text { MI2 }[41] \\
{[\mathrm{g} / 10 \mathrm{~min}]}\end{array}$ & $\begin{array}{c}\boldsymbol{M}_{\mathbf{w}}{ }^{b} \\
{\left[\times 10^{-3}\right]}\end{array}$ & $\boldsymbol{M}_{\mathrm{w}} / \boldsymbol{M}_{\mathrm{n}}$ & $\begin{array}{l}T_{\mathbf{m}}{ }^{c} \\
{\left[{ }^{\circ} \mathrm{C}\right]}\end{array}$ & $\begin{array}{c}\text { Crystallinity }^{\mathrm{d}} \\
\text { [wt.\%] }\end{array}$ \\
\hline 1 & TIBAL [100] & PE8 & 7,810 & 11 & 53 & 2.2 & 122.3 & 49.0 \\
\hline 2 & Al-1 [50] & PE9 & 7,860 & 11 & 54 & 2.6 & 122.9 & 52.3 \\
\hline 3 & Al-1 [100] & PE10 & 7,640 & 11 & 53 & 2.6 & 122.2 & 50.2 \\
\hline 4 & Al-1 [200] & PE11 & 6,880 & 11 & 56 & 2.6 & 123.0 & 51.9 \\
\hline 5 & Al-1 [300] & PE12 & 6,570 & 10 & 55 & 2.6 & 123.1 & 53.5 \\
\hline 6 & Al-1 [500] & PE13 & 5,810 & 10 & 56 & 2.7 & 123.2 & 53.4 \\
\hline $7^{\mathrm{e}}$ & TIBAL [200] & PE14 & 2,210 & 6.2 & 64 & 2.7 & 132.2 & 66.3 \\
\hline $8^{\mathrm{e}}$ & Al-1 [200] & PE15 & 2,850 & 5.3 & 68 & 3.2 & 132.0 & 70.3 \\
\hline
\end{tabular}

${ }^{a}$ Reaction conditions: supp-Zr-1 $=2 \mathrm{mg}, T=85^{\circ} \mathrm{C}, 60 \mathrm{~min}$, iso-butane $41.25 \mathrm{~g}, 1$-hexene $2.44 \mathrm{wt} \%$, ethylene $25 \mathrm{barg}$ $(6 \mathrm{wt} \%), \mathrm{H}_{2} 800 \mathrm{ppm} .{ }^{b}$ Determined by GPC. ${ }^{c}$ Determined by DSC from second run. ${ }^{d}$ Calculated from $\left[\left(\Delta H_{\mathrm{m}} / \Delta H^{0} \mathrm{~m}\right) \times\right.$ 100], where $\Delta H_{m}$ is the heat of fusion of the sample (in $\mathrm{J} / \mathrm{g}$ ) determined by DSC and $\Delta H^{0}{ }_{m}$ is the theoretical heat of fusion for $100 \%$ crystalline PE (293 J/g). [30] ${ }^{e}$ Without 1 -hexene.

The rheological fingerprints of the PEs were next studied. Interestingly, the strength of the shear thinning in the modulus of the complex viscosity $\left(\left|\eta^{*}\right|\right)$ as a function of the frequency ( $\omega)$ plot (Figure $4 a-b$ ) was found to be the same for all samples; the different viscosity values 
at low frequency $\left(1 \mathrm{rad} \cdot \mathrm{s}^{-1}\right)$ could be accounted to $M_{\mathrm{w}}$ effects [22].Error! Bookmark not defined. Notably, all van Gurp-Palmen curves were superimposable and compatible with purely linear PEs (Figure $4 \mathrm{c}-\mathrm{d}$ ). In fact, a phase angle $\delta$ of ca. $90^{\circ}$ at low $\left|\mathrm{G}^{*}\right|$ values was observed regardless of the amount of Al-1 employed. Given that such behaviour has been observed both in the presence and in the absence of the comonomer, the competition between the insertion of 1-hexene and the Al-alkenyl, detrimental for LCB formation, can be excluded [42].
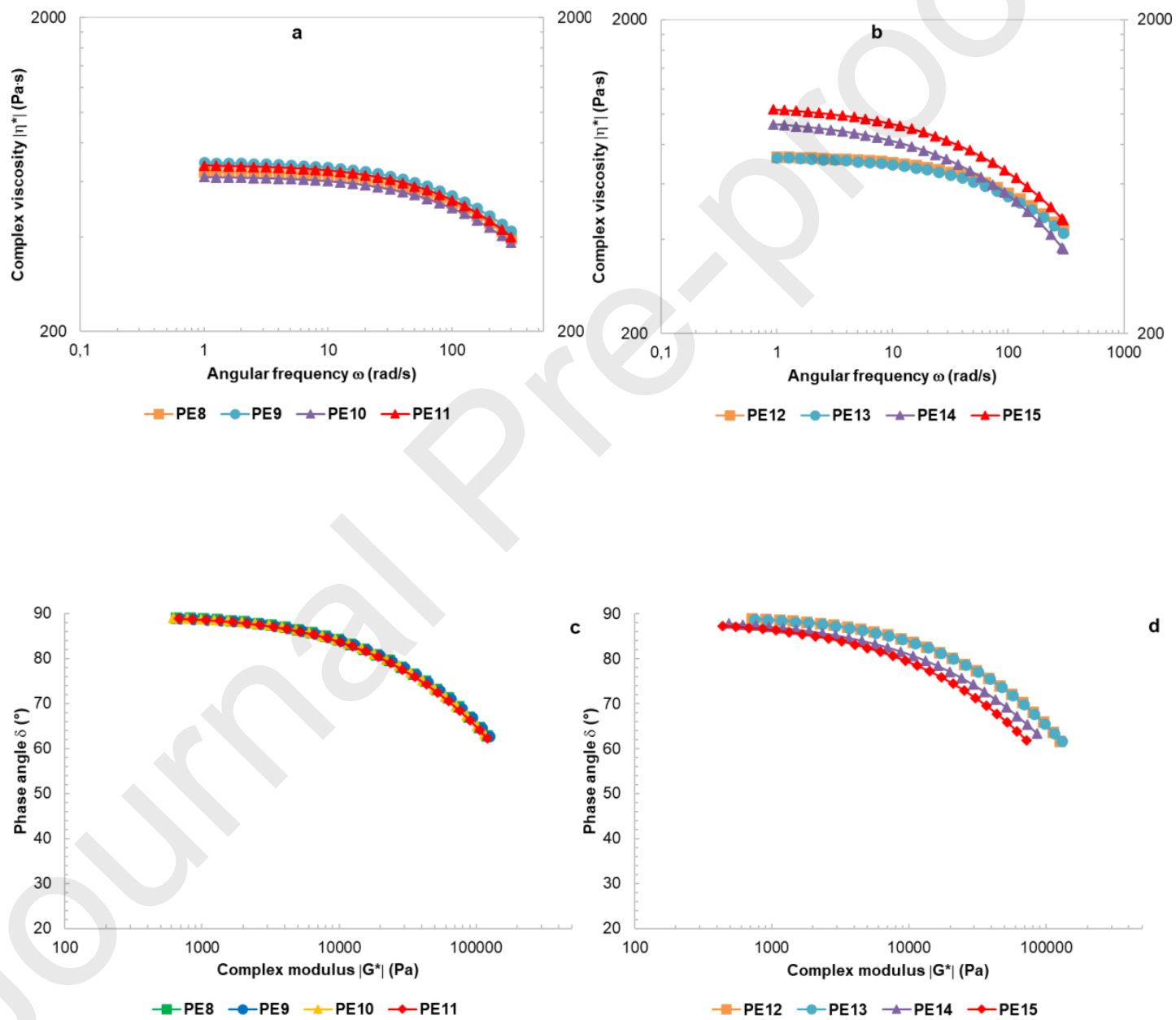

Figure 4. Rheological properties of the PEs obtained with supp-Zr-1/TIBAL/Al-1. (a, b) complex viscosity $\left(\left|\eta^{*}\right|\right)$ vs angular frequency $(\omega)$ plot, $(\mathrm{c}, \mathrm{d}) \mathrm{vGP}$ plot. Shear strain $(\gamma) 10 \%$, angular frequencies $(\omega)$ from 1 to $250 \mathrm{rad} \cdot \mathrm{s}^{-1}$ and $\mathrm{T}=190^{\circ} \mathrm{C}$. 
These results highlight that, unlike the tests conducted under homogeneous conditions, the use of the Al-alkenyl has no influence on the molecular architecture of the PEs generated under heterogeneous conditions: that leads to essentially linear PEs in all cases. It is tentatively proposed that LCB generation is unfavourable under heterogeneous conditions due to the steric effects exerted by the silica support [24], reducing the accessibility of the metal centre eventually impeding the formation of the $\mathrm{Zr}$-Al bimetallic species/insertion of the octenyl moiety of Al-1 [43].

\subsection{DFT studies on the LCB formation with $(n \mathrm{BuCp})_{2} \mathrm{ZrCl}_{2}$ system.}

In this study, we aimed at rationalizing the mechanism of formation of long-chain branches during polymerization of ethylene with a $(n \mathrm{BuCp})_{2} \mathrm{ZrCl}_{2}$ system, in the presence of an Alalkenyl compound, by theoretical computations of the first, second and third insertion steps. Experimentally, the use of the active $\left[(n \mathrm{BuCp})_{2} \mathrm{ZrMe}\right]^{+}$catalyst has the known tendency to produce highly selective linear PE [23]. In agreement with this observation, computed (first, second and third) insertions of ethylene were kinetically and thermodynamically favourable (Figure S7): $9.1 \mathrm{kcal} \cdot \mathrm{mol}^{-1}$ being the highest barrier to overcome in the first insertion of ethylene and all subsequent products stabilising by ca. $20 \mathrm{kcal} \cdot \mathrm{mol}^{-1}$ each insertion step.

The role of the co-catalyst, modelled here by $i \mathrm{BuAl}(\text { oct-7-en-1-yl) })_{2}(\mathbf{A l}-\mathbf{1})$, is first proposed to undergo a coordination step to a vacant active site on the catalyst [44]. This allows for an initial interaction that is comparable, or in competition, with the coordination of ethylene. The coordination of the co-catalytic species was computed assuming three possible geometrical organoaluminium isomers, dependant on the position of the Al-alkyl and Al-Alkenyl chains with respect two both metal atoms (Scheme 2). 


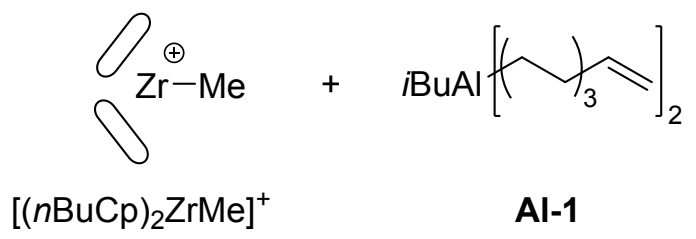

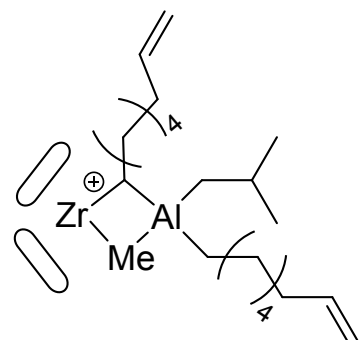

Isomer A

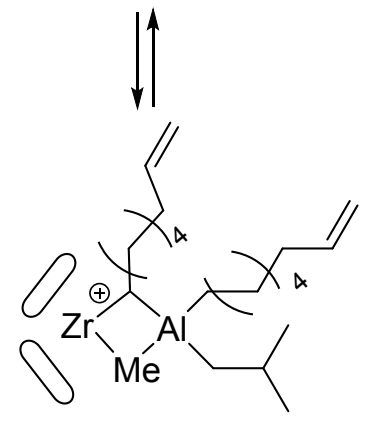

Isomer B

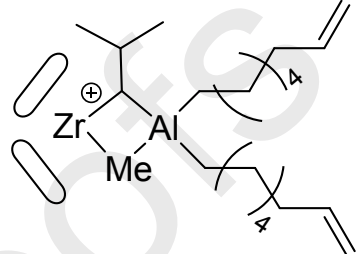

Isomer C

Scheme 2. Isomers of $\mathrm{Zr} / \mathrm{Al}$ heterobimetallic complexes obtained upon coordination of $\mathbf{A l}-\mathbf{1}$ to $\left[(n \mathrm{BuCp})_{2} \mathrm{ZrMe}\right]^{+}$. Each isomer presented depends on the positioning of the alkyl and alkenyl chains.

The bimetallic isomers generated differ by the way in which both metal atoms are bridged; in cases of isomers A and B, the 'bridge' formed is via the alkenyl oct-7-en-1-yl chain, while isomer $\mathrm{C}$ exhibits a $\mathrm{Zr}-i \mathrm{Bu}-\mathrm{Al}$ bridge. As shown in Table 4, the coordination of isomer $\mathrm{B}$ produces the most stabilising interaction with respect to isomers $\mathrm{A}$ and $\mathrm{C}$. Note that the energies are discussed with respect to the various enthalpies computed [45].

Table 4. A comparison between the respective coordination energies (Enthalpy) of the co-catalyst (isomer B) and monomer species to the $\left[(n \mathrm{BuCp})_{2} \mathrm{Zr}-\mathrm{R}\right]^{+}$catalyst.

\begin{tabular}{|c|c|c|}
\hline Isomer B $-\left[(n \mathrm{BuCp})_{2} \mathrm{Zr}-\mathrm{R}\right]^{+}$ & $\begin{array}{c}\text { Al-1 Coordination } \\
\left(\mathrm{kcal} \cdot \mathrm{mol}^{-1}\right)\end{array}$ & $\begin{array}{c}\text { Ethylene coordination } \\
\left(\mathrm{kcal} \cdot \mathrm{mol}^{-1}\right)\end{array}$ \\
\hline $1^{\text {st }}$ Insertion ( $\mathrm{R}=$ methyl) & -6.5 & -7.2 \\
\hline $2^{\text {nd }}$ Insertion ( $\mathrm{R}=n$-propyl) & -5.7 & -6.0 \\
\hline $3^{\text {rd }}$ Insertion ( $\mathrm{R}=n$-pentyl) & -7.0 & -6.1 \\
\hline
\end{tabular}

The initial assessment, comparing the coordination energies of Al-1 and ethylene monomer, highlighted a direct competition between both moieties. For the first three coordination steps, both ethylene monomer and A1-1 provide varying amounts of stability to 
the $\left[(n \mathrm{BuCp})_{2} \mathrm{ZrMe}\right]^{+}$catalyst. Generally, the A1-1 coordination affinity increases as the chain length $(\mathrm{R})$ increases; the difference between either monomer or co-catalyst coordination is inadequate to suggest a preference at this stage.

If we are to assume a path where the coordination of Al-1 takes place, the coordination energies are sufficiently fragile to warrant a dissociation or splitting of the bimetallic $\mathrm{Zr}$-(oct7-en-1-yl)-Al bridge. Conducting a transition state search introduced two mechanisms for the first insertion of ethylene relative to the starting $\mathrm{Zr} / \mathrm{Al}$ bimetallic species

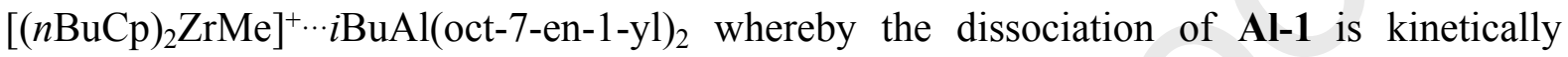
favoured. The dissociative pathway presents a transition state barrier that is more accessible by $39 \mathrm{kcal} \cdot \mathrm{mol}^{-1}$, relative to an ethylene insertion whilst the co-catalyst remains coordinated.

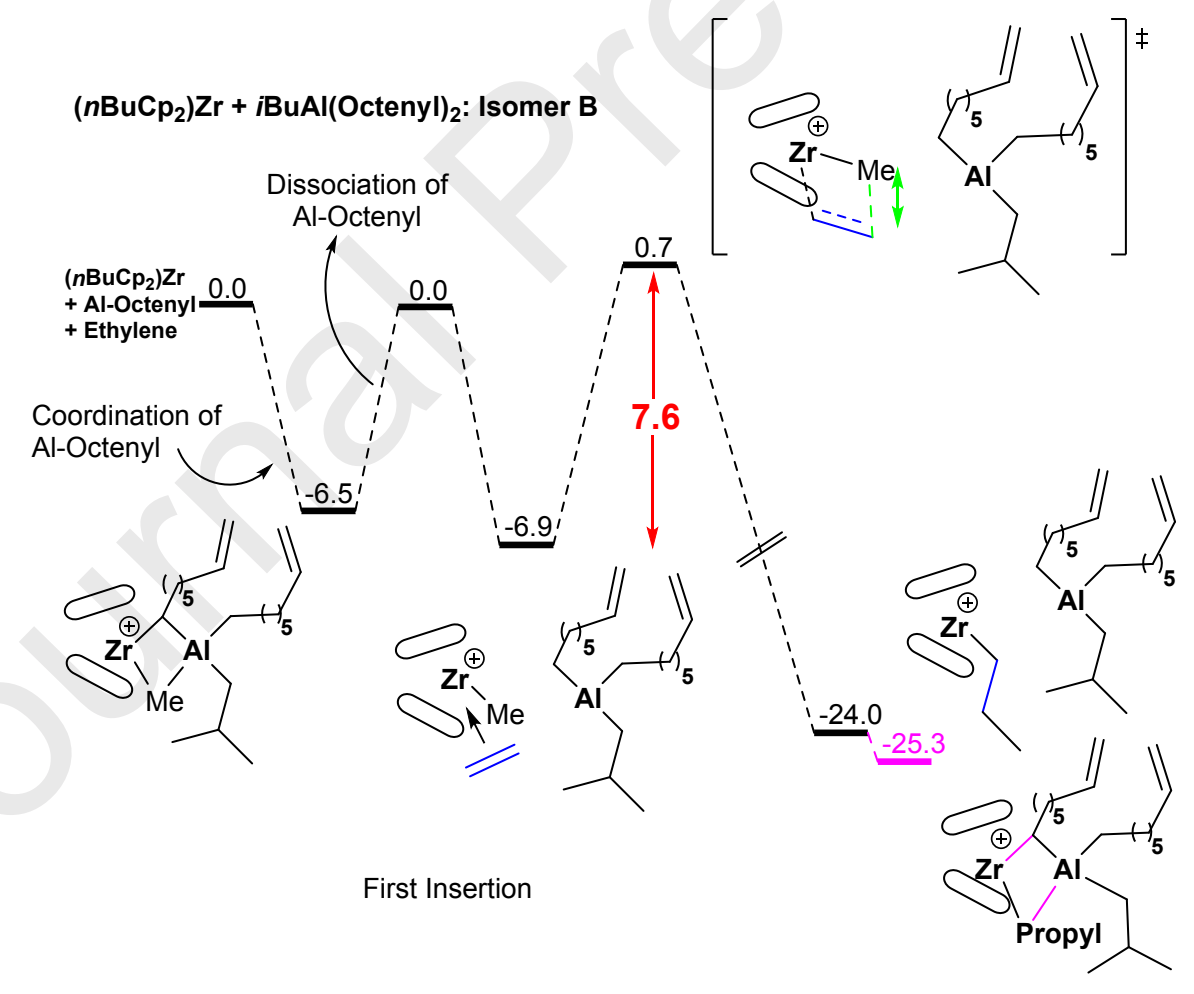

Scheme 3. The profile showing the reactivity of an insertion of ethylene in the presence of Al-1 co-catalyst. Note that the dissociation of the co-catalyst occurs as ethylene is coordinated and inserted. The product is exergonic and the re-coordination of the co-catalyst provides little stability to re-form the bimetallic $(n \mathrm{BuCp})_{2} \mathrm{Zr}(n \mathrm{Pr})-$ $i \mathrm{BuAl}(\text { oct-7-en-1-yl) })_{2}$ species. 
Consequently, the dissociation of the co-catalyst is considered a first step allowing an insertion of ethylene monomer (Scheme 3). The way in which this occurs falls to either bimetallic bridge breaking; either the Al-alkyl or Al-alkenyl bridge. The respective bonds breaking owes to the formation of different products: the dissociated A1-1 co-catalyst and catalyst, or a new $\mathrm{Zr}$-alkenyl species due to a chain shuttling of oct-7-en-1-yl from the cocatalyst to the $\left[(n \mathrm{BuCp})_{2} \mathrm{ZrMe}\right]^{+}$catalyst. With regards to the second insertion, following the notion that a dissociation occurs prior to ethylene coordination/insertion, the energy required to break the $\mathrm{Al}-\left(\right.$ oct-7-en-1-yl) bridge is $5.0 \mathrm{kcal} \cdot \mathrm{mol}^{-1}$ being comparable with the $\mathrm{Al}-n \mathrm{Pr}$ bond demanding $5.7 \mathrm{kcal} \cdot \mathrm{mol}^{-1}$ to split. The weakness of the Al-alkenyl bond suggests that a chain transfer mechanism is less likely, but with a difference of $0.7 \mathrm{kcal} \cdot \mathrm{mol}^{-1}$ it is inconclusive. A competition can be thought to exist between the respective bonds breaking allowing the dissociation of the co-catalyst.

As shown in Scheme 4, if one assumes a pathway whereby an insertion of ethylene incurred a chain transfer from the co-catalyst, a Zr-(oct-7-en-1-yl) species is produced along with a new co-catalytic species. Further insertions of ethylene were computed and the following profile demonstrates the reactivity for the second insertion of ethylene following a chain transfer step (Figure S9). This is an exothermic pathway with a very facile transition state barrier of $4.6 \mathrm{kcal} \cdot \mathrm{mol}^{-1}$, leading to a stable product that now has a very long alkenyl group after just two insertions of ethylene monomer. Interestingly, the interaction of ethylene provides almost $11.4 \mathrm{kcal} \cdot \mathrm{mol}^{-1}$ in stability relative to a chain transfer prior to insertion. This gives rise to the hypothesis that the $\left[(n \mathrm{BuCp})_{2} \mathrm{ZrMe}\right]^{+}$catalyst is further stabilised by the ethylene monomer in contrast to the co-catalyst; this encourages the facile growth of a vinyl terminated ethylene chain after a transmetalation step. 

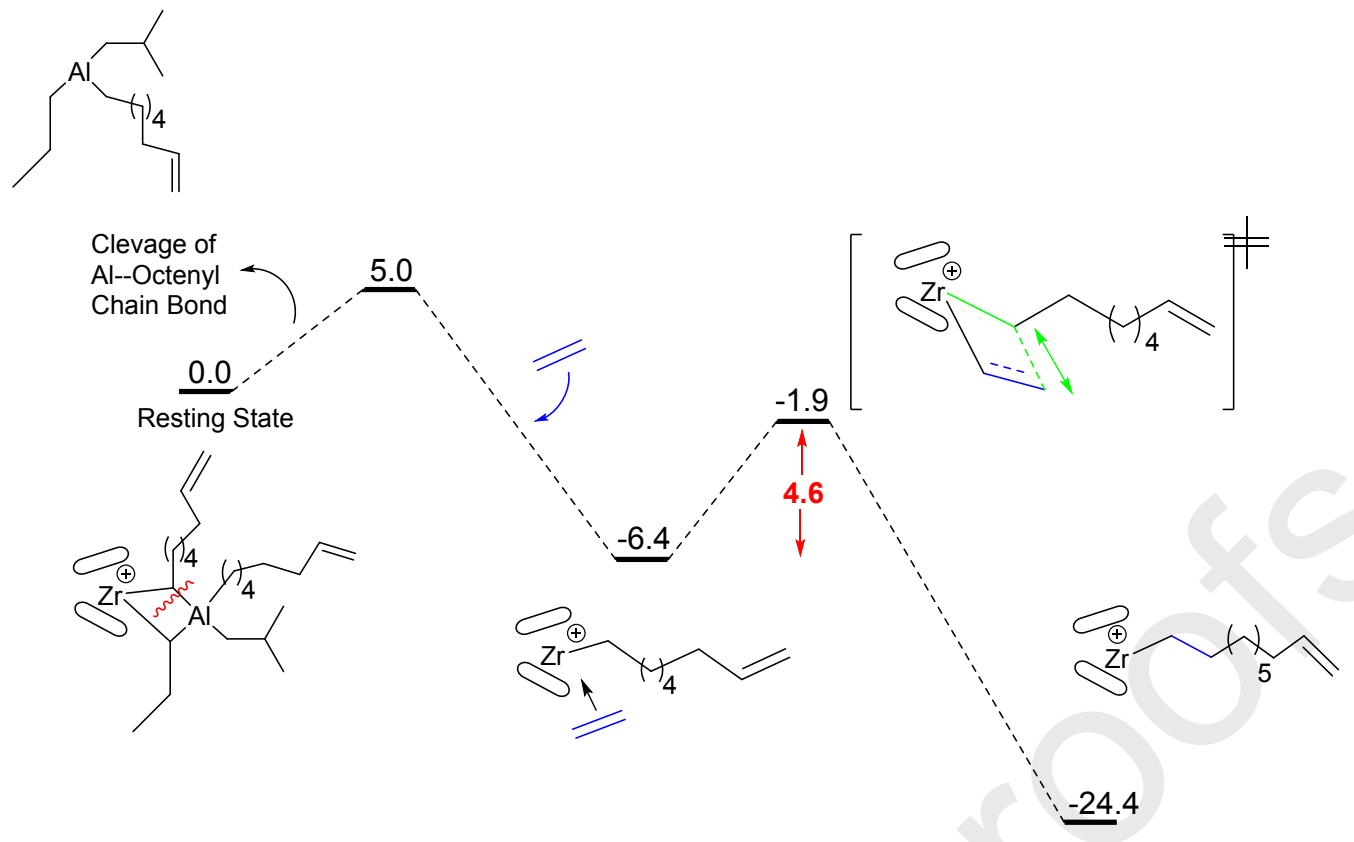

Scheme 4. The profile showing the reactivity of an insertion of ethylene after a chain transfer from the co-catalyst generating a $\mathrm{Zr}$-alkenyl moiety. Ethylene insertion is very accessible and produces a stable exergonic product.

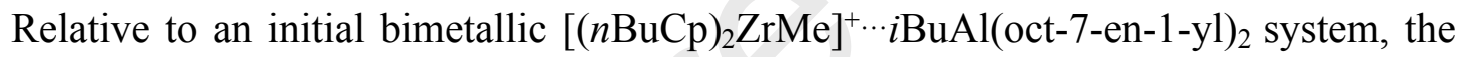
splitting of an Al-alkyl bridge poses a question into the ability of the co-catalyst to recoordinate after subsequent insertions of ethylene. In order to examine how the re-coordination of the co-catalyst may influence the competition induced on the catalyst and monomer interaction, an investigation into the way in which the A1-1 co-catalyst coordinates to $\left[(n \mathrm{BuCp})_{2} \mathrm{Zr}(\mathrm{R})\right]^{+}$was conducted. Two heterobimetallic species were hypothesized: one formed via coordination through the oct-7-en-1-yl ligand on the co-catalyst or another one formed via coordination/insertion of a terminal vinyl group present on the A1-1 oct-7-en-1-yl ligand (see Scheme 5).

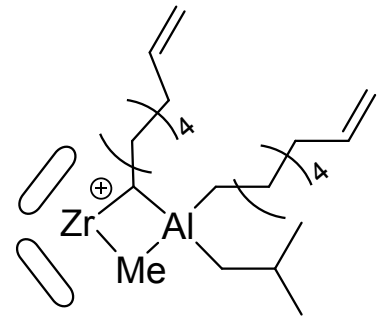

Alkenyl Bridge Coordination

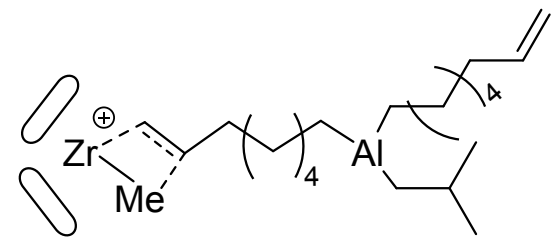

Vinyl Group Coordination 
Scheme 5. The formation of the heterobimetallic species via either i) (left) an alkenyl bridge coordination (ABC): formation of a Zirconium-Alkenyl-Aluminium three-centred bond ii) (right) a vinyl group coordination (VGC) from the oct-7-en-1-yl ligand present on the A1-1 co-catalyst.

Formation of either heterobimetallic species (either ABC or VGC) introduces another variable that hinders the possible coordination/insertion of ethylene. As the chain propagates, assuming the previously discussed co-catalyst dissociation, the likelihood of re-coordination through an alkenyl bridge formation decreases (Table 5). On the contrary, the coordination of a terminal vinyl group from the A1-1 co-catalyst offers a progressively stabilising coordination regardless of chain length. This trend suggests that the way in which the A1-1 co-catalyst coordinates to the catalyst (how the two species are bridged) directly influences the way in which an ethylene chain propagates.

Table 5. The various coordination energies (Enthalpy) producing an ABC type heterobimetallic species, an ethylene monomer coordination or an VGC heterobimetallic species respectively.

\begin{tabular}{|c|c|c|c|}
\hline $\begin{array}{c}\text { Isomer B - } \\
{\left[(n \mathrm{BuCp})_{2} \mathrm{Zr}-\mathrm{R}\right]^{+}}\end{array}$ & $\begin{array}{c}\text { Al-1 } \\
\text { coordination } \\
\left(\mathbf{k c a l} \cdot \mathbf{m o l}^{-1}\right) \\
\end{array}$ & $\begin{array}{c}\begin{array}{c}\text { Ethylene } \\
\text { coordination } \\
\left(\mathbf{k c a l} \cdot \mathrm{mol}^{-1}\right)\end{array} \\
\end{array}$ & $\begin{array}{c}\text { Al-1 } \\
\text { coordination via vinyl group } \\
\text { of an oct-7-en-1-yl ligand }\end{array}$ \\
\hline $1^{\text {st }}$ Insertion ( $\mathrm{R}=$ methyl) & -6.5 & -7.2 & -7.4 \\
\hline $2^{\text {nd }}$ Insertion ( $\mathrm{R}=n$-propyl) & -1.3 & -6.0 & -7.0 \\
\hline $3^{\text {rd }}$ Insertion ( $\mathrm{R}=n$-pentyl) & -0.9 & -6.1 & -8.4 \\
\hline
\end{tabular}

The vinyl group coordination offers an increasingly stabilizing interaction to the $\left[(n \mathrm{BuCp})_{2} \mathrm{ZrMe}\right]^{+}$catalyst at each insertion step. The competition described involves the coordination/insertion of either monomer (ethylene) or vinyl group from the co-catalyst; this produces either a linear or branched PE product, respectively. An investigation into the relative mechanistic pathway was conducted: comparing a coordination/insertion of both an ethylene monomer and vinyl group coordination/insertion (Scheme 6).

For comparative purposes, an insertion of 1-hexene monomer was computed (Figure S10). A transition state barrier of $12.1 \mathrm{kcal} \cdot \mathrm{mol}^{-1}$ implies a relatively accessible insertion 
pathway, whilst only being exothermic by $6.4 \mathrm{kcal} \cdot \mathrm{mol}^{-1}$. Yet, the initial coordination of 1 hexene is less favoured as compared with those calculated both for ethylene monomer and for A1-1 (ABC and VGC included): $-5.5 \mathrm{kcal} \cdot \mathrm{mol}^{-1} \mathrm{vs} .-7.2 \mathrm{kcal} \cdot \mathrm{mol}^{-1}$ or $-6.5 /-7.4 \mathrm{kcal} \cdot \mathrm{mol}^{-1}$, respectively. This result is in line with experimental observations that 1-hexene is hardly incorporated using an $\left[(n \mathrm{BuCp})_{2} \mathrm{ZrMe}\right]^{+}$catalyst [23]. Thus, the formation of an $\mathrm{Zr} / \mathrm{Al}$ heterobimetallic species appears to favour a vinyl group insertion, generating a suitable environment for LCB.

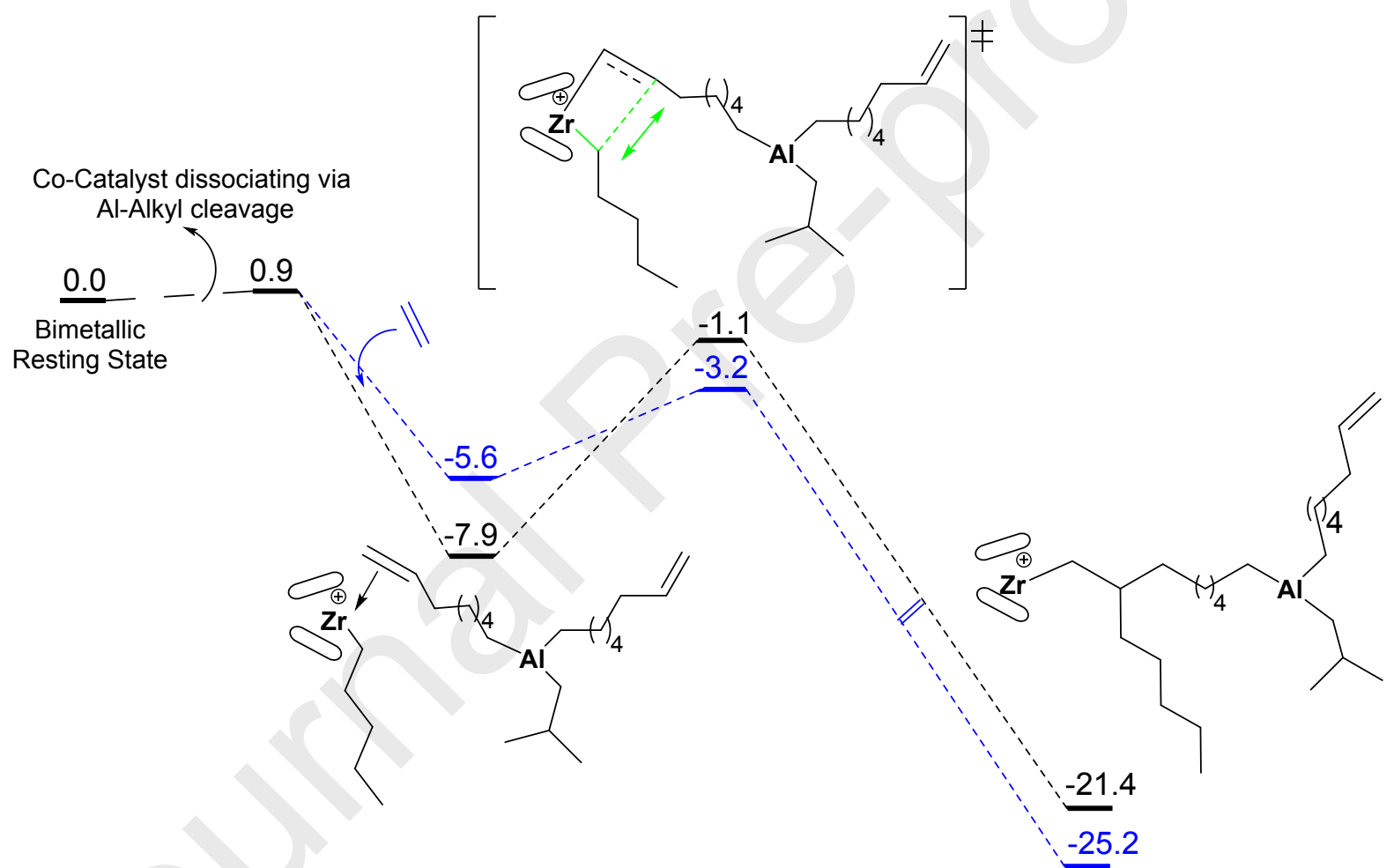

Scheme 6. A comparison between the third vinyl coordination/insertion (black) and ethylene monomer coordination/insertion (blue). For comparisons between the first and second coordination/insertions for either vinyl group and ethylene monomer, please see Figures S7 and S8 in the SI.

The vinyl group coordinating to an $\left[(n \mathrm{BuCp})_{2} \mathrm{Zr}(n \text {-pentyl })\right]^{+}$active species provides a stronger initial interaction relative to ethylene monomer $\left(-2.6 \mathrm{kcal} \cdot \mathrm{mol}^{-1}\right)$. The transition states observed, with respect to the error of our methodology, are indistinguishable from one another highlighting the competitive environment offered via either coordination/insertion. The 
products produced, either linear or branched, indicate that ethylene monomer insertion is favourable by ca. $4 \mathrm{kcal} \cdot \mathrm{mol}^{-1}$; the production of a branched species (towards LCB) therefore is considered plausible but a 'rare' event relative to an ethylene monomer coordination/insertion.

Chain-growth is directly influenced by the coordination of the A1-1 co-catalyst and how this occurs. Although providing a distinct pathway to produce a linear polymeric product, as the chain length on the catalyst increases, the inclination for a vinyl group coordination eventually generating a branched product - appears to become more favourable with respect to the proposed mechanism of coordination/insertion.

\section{Conclusions}

An Al-alkenyl compound (Al-1) has been employed as LCB-promoter in the polymerization of ethylene catalyzed by $(n \mathrm{BuCp})_{2} \mathrm{ZrCl}_{2} / \mathrm{MAO}(\mathbf{Z r}-1 / \mathrm{MAO})$ systems. Under homogeneous conditions, in the absence of Al-1 and at low ethylene pressure (4 barg), the presence of a minimal, yet detectable amount of LCB was observed by rheological analyses and confirmed by ${ }^{13} \mathrm{C}$ NMR spectroscopy. This is overall consistent with the previously reported poor ability/ineffectiveness of $\mathbf{Z r - 1}$ catalyst systems to incorporate (in situ generated) macromonomers $[22,23]$. On the other hand, the rheological behaviour of the PE synthesized in the presence of the Al-alkenyl co-reactant (PE3) was found to be compatible with a significantly branched architecture. Such branching is likely to originate from the insertion of the pending vinyl moiety of $\mathbf{A l - 1}$ into a $\mathrm{Zr}-\mathrm{C}_{\text {polymeryl }}$ bond followed by the $\mathrm{Al}$ to $\mathrm{Zr}$ transmetallation generating a growing side-chain. Notably, the rheological characterization suggested that the LCB density of PE3 generated with the $\mathbf{Z r - 1}$ homogeneous catalyst was comparable to that of the PE prepared under similar reaction conditions with the EBTHI-based catalyst [21]; this indicates that $\mathbf{A l - 1}$ is an efficient LCB promoter regardless the nature of the 
metallocene involved (at least with the two systems we have studied so far). This is remarkable since $\mathbf{Z r - 1}$ is known to incorporate comonomers (i.e., 1-hexene) to a much lower extent than EBTHI systems $[23,28]$. It is proposed that the insertion of the octenyl group of Al-1 is facilitated by the formation of intermediary $\mathrm{Zr} / \mathrm{Al}$ heterobimetallic species. Indeed, DFT calculations indicated that such event is more favourable than the incorporation of a comonomer, such as 1-hexene.

A set of experiments performed at higher monomer pressure ( $9 \mathrm{barg})$ afforded insoluble samples (PE4-PE7), apparently crosslinked PEs, regardless of the amount of Al-1 employed ( $0-1,000$ equiv.). This highlighted that a more ample control over branching/crosslinking could be achieved with this homogeneous system by tuning the polymerization conditions, allowing for the design and production of new materials exhibiting the desired topological- and mechanical features.

Unexpectedly, only purely linear PEs were recovered upon using the silica-supported version of $\mathbf{Z r - 1}$, regardless of the amount of Al-1 employed. This is tentatively accounted to steric effects exerted by the silica support [24], reducing the accessibility of the $\mathrm{Zr}$ centre and impeding its interaction with the Al-alkenyl co-reactant.

Acknowledgements: LM is a senior member of the Institut Universitaire de France. CalMip is acknowledged for a generous grant of computing time.

Funding sources: This work was gratefully supported by Total SA and Total Research and Technology Feluy (postdoctoral and PhD fellowships to OS, LP and KMC).

\section{Appendix A: Supplementary data}


Supporting information to this article (NMR spectroscopy and rheological analyses of polymers, computational details, cartesian coordinates) can be found online at DOI:

\section{References and notes}

[1] L. Resconi, L. Cavallo, A. Fait, F. Piemontesi, Selectivity in propene polymerization with metallocene catalysts, Chem. Rev. $100 \quad$ (2000) 1253-1346. https://doi.org/10.1021/cr9804691.

[2] S.-Y. Lai, J.R. Wilson, G.W. Knight, J.C. Stevens, P.-W. Chum, Elastic substantially linear olefin polymers, U.S. Pat. 5,272,236, 1993 (to Dow Chemical co.).

[3] P. Brant, J.A.M. Canich, A.J. Dias, R.L. Bamberger, G.G. Licciardi, P.M. Henrichs, Long chain branched polymers and a process to make long chain branched polymers, WO Pat. 94/07930, 1994 (to ExxonMobil Chemical co.).

[4] Y.S. Kim, C.I. Chung, S.Y. Lai, K.S. Hyum, Melt rheological and thermodynamic properties of polyethylene homopolymers and poly(ethylene/ $\alpha$-olefin) copolymers with respect to molecular composition and structure, J. Appl. Polym. Sci. 59 (1996) 125-137. https://doi.org/10.1002/(SICI)1097-4628(19960103)59:1<125::AID-APP18>3.0.CO;2$\mathrm{Z}$.

[5] P.S. Chum, W.J. Kupper, M.J. Guest, Materials properties derived from INSITE metallocene catalysts, Adv. Mater. (12) 2000 1759-1767. https://doi.org/10.1002/15214095(200012)12:23<1759::AID-ADMA1759>3.0.CO;2-7.

[6] A. Malmberg, E. Kokko, P. Lehmus, B. Lofgren, J.V. Seppälä, Long-chain branched polyethene polymerized by metallocene catalysts $\mathrm{Et}[\mathrm{Ind}]_{2} \mathrm{ZrCl}_{2} / \mathrm{MAO}$ and $\mathrm{Et}\left[\mathrm{IndH}_{4}\right]_{2} \mathrm{ZrCl}_{2} / \mathrm{MAO}, \quad$ Macromolecules $\quad 31 \quad$ (1998) $\quad$ 8448-8454. https://doi.org/10.1021/ma980522n. 
[7] E. Kokko, P. Pietikäinem, J. Koivunen, J.V. Seppälä, Long-chain-branched polyethene by the copolymerization of ethene and non-conjugated $\alpha, \omega$-dienes, J. Polym. Sci. 39 (2001) 3805-3817. https://doi.org/10.1002/pola.10033.

[8] P. Pietikäinem, R. Väänänen, J.V. Seppälä, Copolymerization of ethylene and nonconjugated dienes with $\mathrm{Cp}_{2} \mathrm{ZrCl}_{2} / \mathrm{MAO}$ catalyst system, Eur. Polym. J. 35 (1999) 10471055. https://doi.org/10.1016/S0014-3057(98)00192-X.

[9] P. Pietikäinem, J.V. Seppälä, L. Ahjopalo, L;-O. Pietilä, Copolymerization of ethylene and non-conjugated dienes with $\mathrm{Cp}_{2} \mathrm{ZrCl}_{2} / \mathrm{MAO}$ catalyst system: effect of polymerization temperature on the copolymer structure, Eur. Polym. J. 36 (2000) 183192. https://doi.org/10.1016/S0014-3057(99)00053-1.

[10] N. Naga, Y. Imanishi, Copolymerization of ethylene and 1,7-octadiene, 1,9-decadiene with zirconocene catalysts, Macromol. Chem. Phys. 203 (2002) 2155-2162. https://doi.org/10.1002/1521-3935(200211)203:15<2155::AID-MACP2155>3.0.CO;27.

[11] A. Williamson, G. Fink, Alternating copolymers of ethylene and diolefins containing pendent functional groups, Macromol. Chem. Phys. 204 (2003) 1178-1190. https://doi.org/10.1002/macp.200390091.

[12] M. Rätzsch, Reaction mechanism to long-chain branched polypropylene, J. Macromol. Sci. A. 36 (1999) 1759-1769. https://doi.org/10.1081/MA-100101626.

[13] J. Ardakani, Y. Jahani, C. Zhou, Effect of electron beam irradiation dose on the rheology, morphology, and thermal properties of branched polypropylene/polybutene-1 blend, Polym. Eng. Sci. 54 (2014) 1747-1756. https://doi.org/10.1002/pen.23716.

[14] B. Lu, T.C. Chung, Synthesis of long chain branched polypropylene with relatively welldefined molecular structure, Macromolecules $32 \quad$ (1999) 8678-8680. https://doi.org/10.1021/ma991010r. 
[15] J.S. Parent, A. Bodsworth, S.S. Sengupta, M. Kontopoulou, B.I. Chaudhary, D. Poche, S. Cousteaux, Structure-rheology relationships of long-chain branched polypropylene: Comparative analysis of acrylic and allylic coagent chemistry, Polymer 50 (2009) 8594. https://doi.org/10.1016/j.polymer.2008.11.014.

[16] X.C. Wang, C. Tzoganakis, G.L. Rempel, Chemical modification of polypropylene with peroxide/pentaerythritol triacrylate by reactive extrusion, J. Appl. Polym. Sci. 61 (1996) 1395-1404. https://doi.org/10.1002/(SICI)1097-4628(19960822)61:8<1395::AIDAPP21 $>3.0 . C O ; 2-X$

[17] J.H. Tian, W. Yu, C.X. Zou, The preparation and rheology characterization of long chain branching polypropylene, $\quad$ Polymer $\quad 47 \quad$ (2006) $\quad 7962-7969$. https://doi.org/10.1016/j.polymer.2006.09.042

[18] S. Stanic, G. Gottlieb, T. Koch, L. Gopperl, K. Schmid, S. Knaus, V.-M. Archodoulaki, Influence of Different Types of Peroxides on the Long-Chain Branching of PP via Reactive $\quad$ Extrusion, $\quad$ Polymers $\quad 12 \quad$ (2020) 886-904. https://doi.org/10.3390/polym12040886.

[19] H.J. Lee, J.W. Baek, T.J. Kim, H.S. Park, S.H. Moon, K.L. Park, S.M. Bae, J. Park, B.Y. Lee, Synthesis of Long-Chain Branched Polyolefins by Coordinative Chain Transfer Polymerization, $\quad$ Macromolecules $\quad 52 \quad$ (2019) 9311-9320. https://doi.org/10.1021/acs.macromol.9b01705

[20] M.W. Holtcamp, G.S. Day, J.R. Hagadorn, O.J. Palafow, R. Mathiamagan, J.M. Canich, Aluminum alkyls with pendant olefins for polyolefin reactions, WO Pat. Appl. 2017039995 A1 (to ExxonMobil co.).

[21] O. Santoro, L. Piola, K. Mc Cabe, O. Lhost, K. Den Dauw, A. Vantomme, A. Welle, L. Maron, J.-F. Carpentier, E. Kirillov, Long-Chain Branched Polyethylene via Coordinative Tandem Insertion and Chain-Transfer Polymerization Using rac- 
$\{$ EBTHI $\} \mathrm{ZrCl}_{2} / \mathrm{MAO} / \mathrm{Al}$-alkenyl Combinations: An Experimental and Theoretical

Study, $\quad$ Macromolecules $\quad 53$

$53 \quad(2020)$

$8847-8857$.

https://doi.org/10.1021/acs.macromol.0c01671.

[22] E. Kokko, A. Malmberg, P. Lehmus, B. Löfgren, J.V. Seppälä, Influence of the catalyst and polymerization conditions on the long-chain branching of metallocene-catalyzed polyethenes, J. Polym. Chem. Sci. A Polym. Chem. 38 (2000) 376-388. https://doi.org/10.1002/(SICI)1099-0518(20000115)38:2\%3C376::AID-

POLA12\%3E3.0.CO;2-5

[23] Q. Yang, M.D. Jensen, M.P. McDaniel, Alternative View of Long Chain Branch Formation by Metallocene Catalysts, Macromolecules (43) 2010 8836-8852. https://doi.org/10.1021/ma101469j.

[24] G.B. Galland, M. Seferin, R.S. Mauler, J.H.Z. Dos Santos, Linear low-density polyethylene synthesis promoted by homogeneous and supported catalysts, Polym. Int. 48 (1999) 660-664. https://doi.org/10.1002/(SICI)10970126(199908)48:8\%3C660::AID-PI212\%3E3.0.CO;2-L.

[25] M.D. Jensen, Q. Yang, Y. Yu, M.P. McDaniel, Kinetics of Long-Chain Branch Formation in Polyethylene, ACS Catal. $8 \quad$ (2018) 725-737. https://doi.org/10.1021/acscatal.7b03267.

[26] H.C. Welborn, V.R. Sagar, E.E. Poirot, J.A.M. Canich, T.J. Burkhardt, Polymerization process and catalyst systems useful therein, WO Patent 1996000246 A1 (to Exxon Chemical co).

[27] M.O. Jejelowo, R.L. Bamberger, Polymerization catalysts, their production and use. U.S. Pat. 5,470,811 (to Exxon Chemicals co).

[28] C. Lehtinen, B.A. Löfgren, A comparison of (n-butCp) ${ }_{2} \mathrm{ZrCl}_{2}$ and other simple metallocenes with bridged $\mathrm{Et}(\mathrm{Ind})_{2} \mathrm{ZrCl}_{2}$ and $\mathrm{Me}_{2} \mathrm{Si}(\mathrm{Ind})_{2} \mathrm{ZrCl}_{2}$ catalysts in 
ethene/propene copolymerization, Eur. Polym. J. 33 (1997) 115-120. https://doi.org/10.1016/S0014-3057(96)00103-6.

[29] PE1 was isolated under reaction conditions similar to that of ref. 22. In order to have a direct comparison between the present results and our previous contribution, PE2 and PE3 were prepared employing the conditions reported in ref. 21.

[30] S. Wang, C. Wu, M. Q. Ren, R.M.V. Horn, M.J. Graham, C.C. Han, E. Chen, S.Z.D Chen, Liquid-liquid phase separation in a polyethylene blend monitored by crystallization kinetics and crystal-decorated phase morphologies. Polymer 50 (2009) 1025-1033. https://doi.org/10.1016/j.polymer.2008.12.028.

[31] S. Trinkle, C. Friedrich, Van Gurp-Palmen-plot: a way to characterize polydispersity of linear polymers, Rheol. Acta $40 \quad$ (2001) 322-328. https://doi.org/10.1007/s003970000137.

[32] S. Trinkle, P. Walter, C. Friedrich, Van Gurp-Palmen Plot II - classification of long chain branched polymers by their topology, Rheol. Acta 41 (2002) 103-113. https://doi.org/10.1007/s003970200010.

[33] F.J. Stadler, V. Karimkhani, Correlations between the Characteristic Rheological Quantities and Molecular Structure of Long-Chain Branched Metallocene Catalyzed Polyethylenes, Macromolecules $44 \quad(2011)$ $5401-5413$. https://doi.org/10.1021/ma200550c.

[34] F.J. Stadler, H. Munstedt, Correlation between the shape of viscosity functions and the molecular structure of long-chain branched polyethylenes, Macromol. Mater. Eng. 294 (2009) 25-34. https://doi.org/10.1002/mame.200800251.

[35] F.J. Stadler, S. Chen, S. Chen, On "modulus shift" and thermorheological complexity in polyolefins, Rheol. Acta 54 (2015) 695-704. https://doi.org/10.1007/s00397-015-08649. 
[36] Z.-C., Yan, F.J. Stadler, Classification of thermorheolegical complexity for linear and branched polyolefins, Rheol. Acta 57 (2018) 377-388. https://doi.org/10.1007/s00397018-1088-6.

[37] The $d \log \left|\eta^{*}\right| / \operatorname{dlog} \omega$ vs. $\delta$ plots for PE1-PE3, showed a certain deviation from linear relation (Figure S1). This may stem from some machine errors at low torque, although the raw data was manually checked and no anomalies were detected. Another explanation is that the true Newtonian viscosity value, which we could get from the approach proposed, is apparently underestimated; see: F.J. Stadler, H. Munstedt, Numerical description of shear viscosity functions of long-chain branched metallocene-catalyzed polyethylenes, J. Non-Newtonian Fluid Mech. $151 \quad$ (2008) 129-135. https://doi.org/10.1016/j.jnnfm.2008.01.010. On the other hand, the $d \log \left|\eta^{*}\right| / d \log \omega$ vs. $\delta$ plots for PE8-PE15 do not significantly deviate from linear relation (Figure S2), as expected from linear PEs.

[38] T. Hsieh, J.C. Randall, Ethylene-1-Butene Copolymers. 1. Comonomer Sequence Distribution, $\quad$ Macromolecules $\quad 15 \quad$ (1982) 353-360. https://doi.org/10.1021/ma00230a030.

[39] F.J. Stadler, Detecting very low levels of long-chain branching in metallocene-catalyzed polyethylenes, Rheol. Acta 51 (2012) 821-840. https://doi.org/10.1007/s00397-0120642-x.

[40] 1-Hexene is added to the reaction mixture in order to increase the catalyst activity (socalled "comonomer effect"); see for example ref. Error! Bookmark not defined. and references reported therein. An overview of the proposed explanations for such effect is reported in: Q. Wu, A. García-Peñas, R. Barranco-García, M.L. Cerrada, R. Benavente, E. Pérez, J.M.A. Gómez-Elvira, New Insight into the Comonomer Effect through NMR Analysis in Metallocene Catalysed Propene-co-1-Nonene Copolymers, Polymers 11 
(2019) 1266-1287. https://doi.org/10.3390/polym11081266. For the Zr-1-based systems, the activity enhancement is likely to be due to the formation of novel initiating sites by chain transfer immediately after 1-hexene insertion (see for example ref. 22).

[41] The Melt Flow Index (MI2) is defined as the number of grams of polymer extruded in ten minutes as measured by ASTM Method D 1238.

[42] To evaluate the effect of hydrogen on the molecular structure of the final materials, a polymerization was performed at a lower $\mathrm{H}_{2}$ concentration $(500 \mathrm{ppm}$ instead of the standard $800 \mathrm{ppm}$ ) and in the presence of $200 \mathrm{ppm}$ of Al-1. The rheological fingerprints of both samples (van Gurp-Palmen plot, Figure S6) were compatible to that of a linear PE, indicating that the $\mathrm{H}_{2}$ concentration does not have an impact on the LCB formation.

[43] It has to be noted that, compared to the runs conducted with the homogeneous catalyst system, higher monomer pressure was employed under heterogeneous conditions (4/9 vs 25 barg), as customary of such experiments. Under such conditions, the interaction of Al-1 (or in situ-generated macromonomers) with the metal center would be further impeded by the higher ethylene concentration.

[44] C. Ehm, R. Cipullo, P.H.M. Budzelaar, V. Busico, Role(s) of TMA in Polymerization, Dalton Trans. 45 (2016) 6847-6855. https://doi.org/10.1039/C5DT04895H

[45] L. Castro, E. Kirillov, O. Miserque, A. Welle, L. Haspeslagh, J.-F. Carpentier, L. Maron, Are Solvent and Dispersion Effects Crucial in Olefin Polymerization DFT Calculations? Some Insights from Propylene Coordination and Insertion Reactions with Group 3 and 4 Metallocenes, ACS Catal. 5 (2015) 416-425. 
Al-Alkenyl-Induced Formation of Long-Chain Branched Polyethylene via Coordinative Tandem Insertion and Chain-Transfer Polymerization Using $(n \mathrm{BuCp})_{2} \mathrm{ZrCl}_{2} / \mathrm{MAO}$ Systems: An Experimental and Theoretical Study

Orlando Santoro, Lorenzo Piola, Karl Mc Cabe, Olivier Lhost, Katty Den Dauw, Aurélien Vantomme, Alexandre Welle, Laurent Maron, Jean-François Carpentier and Evgueni Kirillov

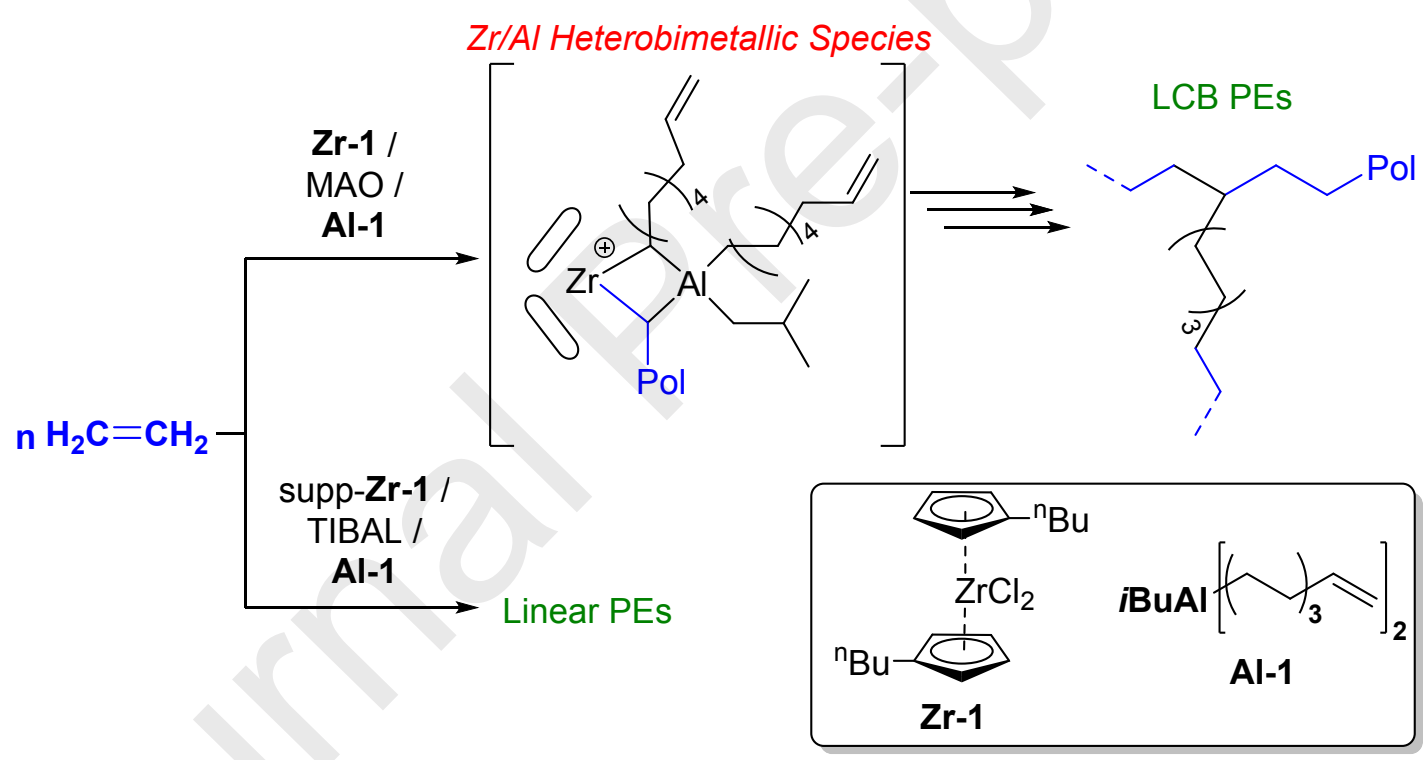


- The Al-alkenyl species $i \mathrm{BuAl}\left(\right.$ oct-7-en-1-yl) ${ }_{2}$ (Al-1) was tested as long-chain branching- (LCB) promoter in the ethylyene polymerization catalyzed by $(n \mathrm{BuCp})_{2} \mathrm{ZrCl}_{2}(\mathbf{Z r}-\mathbf{1})$-based systems, both under homogeneous and heterogeneous conditions.

- While linear polymers were achieved under heterogeneous conditions in all cases, the PE isolated with the homogeneous Zr-1/MAO/Al-1 system exhibited a rheological behavior indicative of LCB.

- Rheological data suggested that the level of LCB in such sample was comparable to that of the PEs synthesized under similar reaction conditions with the previously reported EBTHI/MAO/Al-1 system.

- The process leading to long-chain branching was rationalized considering the formation of $\mathrm{Zr} / \mathrm{Al}$ heterobimetallic species facilitating the Al-1 incorporation via the coordinative tandem insertion and chain-transfer polymerization mechanism.

- The experimental data as well as the proposed LCB-formation pathway were supported by DFT calculations. 
Manuscript Number: EUROPOL-D-21-00180

\section{Author Statement}

Orlando Santoro : investigation, data analysis, writing original draft

Lorenzo Piola : investigation, data analysis, writing original draft

Karl Mc Cabe : theoretical computations, writing original draft

Olivier Lhost : analysis of rheological data

Katty Den Dauw : analysis of NMR spectroscopic data

Aurélien Vantomme : conceptualization, project administration

Alexandre Welle : conceptualization, project administration

Laurent Maron : conceptualization, theoretical computations, supervision

Jean-François Carpentier : conceptualization, project administration, supervision

Evgueni Kirillov : conceptualization, writing original draft, project administration, supervision 